\title{
Development of New Smart Materials and Spinning Systems Inspired by Natural Silks and Their Applications
}

\author{
Jie Cheng ${ }^{1}$ and Sang-Hoon Lee ${ }^{1,2,3 *}$ \\ ${ }^{1}$ Department of Biomedical Engineering, College of Health Science, Korea University, Seoul, South Korea, ${ }^{2}$ Department of \\ Bio-Convergence Engineering, College of Health Science, Korea University, Seoul, South Korea, ${ }^{3}$ KU-KIST Graduate School \\ of Converging Science and Technology, Korea University, Seoul, South Korea
}

Silks produced by spiders and silkworms are charming natural biological materials with highly optimized hierarchical structures and outstanding physicomechanical properties. The superior performance of silks relies on the integration of a unique protein sequence, a distinctive spinning process, and complex hierarchical structures. Silks have been prepared to form a variety of morphologies and are widely used in diverse applications, for example, in the textile industry, as drug delivery vehicles, and as tissue engineering scaffolds. This review presents an overview of the organization of natural silks, in which chemical and physical functions are optimized, as well as a range of new materials inspired by the desire to mimic natural silk structure and synthesis.

OPEN ACCESS

Edited by:

Yongmei Zheng,

Beihang University, China

Reviewed by:

Zhongbing Huang,

Sichuan University, China Liping Wen,

Chinese Academy of Sciences, China

*Correspondence:

Sang-Hoon Lee

dbiomed@korea.ac.kr

Specialty section:

This article was submitted to

Nanobiotechnology,

a section of the journal

Frontiers in Materials

Received: 18 September 2015

Accepted: 23 December 2015

Published: 12 January 2016

Citation:

Cheng J and Lee S-H (2016)

Development of New Smart Materials and Spinning Systems Inspired by Natural Silks and Their Applications.

Front. Mater. 2:74.

doi: 10.3389/fmats.2015.00074
Keywords: silk, protein primary sequence, spinning, hierarchical structure, self-assembly, biomimetic, silkinspired functional materials

\section{INTRODUCTION}

Over the last 5000 years, silk has been widely studied and used in the textile industry; however, many lessons may still be learned from this outstanding natural biological material. A remarkable feature of natural silk is its outstanding toughness, which is superior to that of any of other artificial fiber (Liu et al., 2005; Keten et al., 2010; Omenetto and Kaplan, 2010; Porter et al., 2013; Tokareva et al., 2014). Most researchers believe that the toughness of silk originates from the combined action of the alternating hydrophobic and hydrophilic pattern in the protein primary sequence and the unique spinning process used to prepare the silk fibers. Spiders and silkworms generate a variety of silk fibers. Among the known silk variants, the silk of Bombyx mori (B. mori) and the orb web spider dragline silks of Nephila clavipes and Araneus diadematus are the most widely used one. These particular silks have inspired researchers to develop new smart materials, which is the main topic of this review. Although B. mori silks are not as tough as spider dragline silks, the high yield of these silks through domesticated production has facilitated the use of these silks in a variety of fields, from luxury fabrics to biomedicine, since their development in China thousands of years ago. Spider dragline silk is thought to be the toughest biological material yet identified; however, limitations on methods for mass production of spider silk have contributed to a gap between applications of silkworm silk and spider silk. Researchers recently developed a series of recombinant DNA technologies that enable spider silk production of the large scale (Tokareva et al., 2013). Recombinant technologies permit genetic modifications that can be imparted on the functionalities of spider silks in addition to their extraordinary mechanical properties (Schacht and Scheibel, 2014). Such advances in biotechnology 
have led to a flourishing of spider silk applications that have narrowed the gap with silkworm silk applications (Schacht and Scheibel, 2014).

The hierarchical structures of natural silks are crucial to the silks' strength. The design of materials with hierarchical structures similar to that of silk may contribute to the development of novel high-performance functional materials. Silk proteins are hierarchical amphiphilic block proteins composed of alternating hydrophobic and hydrophilic blocks. Hierarchical amphiphilic patterns drive silk proteins to self-assemble into micelles and play a critical role in silk protein storage inside the glands (Jin and Kaplan, 2003; Askarieh et al., 2010; Hagn et al., 2010; He et al., 2012; Schwarze et al., 2013). Therefore, the synthesis of silk proteins similar to the natural proteins is a key issue in material science. Another critical aspect of silk engineering is the spinning system used to prepare the fibers. Such systems are typically designed to mimic natural spinning mechanisms. The tapered spinning duct of silkworm or spider provides an elongational field during spinning process, which orients the silk protein micelles along the direction of the duct via a shear force, leading to the formation of $\beta$-sheet crystals. The fibers are then drawn away from the spinning ducts either by the legs of the spider or by the "figure eight" movement of the silkworm head to further orient the silk proteins and form $\beta$-sheets. The as-spun silk fibers are composed a hierarchical system of $\beta$-sheet crystal domains and $\alpha$-helix/turn non-crystalline domains, which convey to the silk fibers non-linear material properties and outstanding mechanical properties. Although several reviews of synthetic silk protein morphologies have been published (Altman et al., 2003; Vepari and Kaplan, 2007; Kim et al., 2010, 2014; Rockwood et al., 2011; Tao et al., 2012; Kundu et al., 2014), new materials inspired by silk protein and various spinning methods mimicking spider and silkworm have not been reviewed, despite their importance and extensive applications. In addition, how silk fibers assemble into 3D hierarchical macroscale structures (cocoons and webs) to meet various needs by silkworms and spiders are not summarized until now.

This review presents an overview of the beautiful organizational structures of natural silks from the nanoscale (protein sequence), microscale (spinning) to macroscale (cocoons and webs) aspect and introduces new materials and processes inspired by nature. As shown in Figure 1, the natural silk is produced from the synthesis of silk protein, spinning by shear force and formation of web and cocoon, and understanding of sequence-structure-property interplay is critical in developing smart materials inspired by the spider and silkworm. Here, we described a variety of new materials and applications inspired by silk's hierarchical structures and silk spinning process.

\section{NEW SYNTHETIC NANOMATERIALS INSPIRED BY THE SILK PRIMARY SEQUENCE AND DIRECTED SELF- ASSEMBLY}

Nanomaterials are potentially useful in a variety of applications (Zhang, 2003). As scientists have dreamed of designing nanoscale material macrostructures through bottom-up methods, they have studied mimics of the self-assembly processes used by natural systems, such as silkworms or spiders. The self-assembly of silk inside the gland and spinning duct is a marvelous process. Silk proteins are produced inside glands and stored in relatively high concentrations of up to $\sim 50 \% \mathrm{w} / \mathrm{w}$ without aggregation. Selfassembly among silk proteins into highly ordered micelle cluster structures protects the silk proteins from aggregation. The silk proteins are amphiphilic and consist of alternating hydrophobic and hydrophilic domains with highly conserved C- and N-terminal domains. The hydrophobic interactions between hydrophobic domains constitute the main force driving self-assembly (Jin and Kaplan, 2003). The small hydrophilic domains may remain hydrated inside the micelles, and the terminal domains define the micelle edges, stabilizing the solubilized proteins (Hagn et al., 2010). The hydrophobic domains are dominated by a hydrophobic sequence (GA)n or An, which enables protein chain self-assembly to form $\beta$-sheet-rich crystal structure and gives silk fibers their outstanding mechanical properties. Stimuli-responsive C- and $\mathrm{N}$-terminal domains play a role in fiber formation under shear force. The primary silk protein sequence has been introduced into artificial polypeptides/peptides and polymer-peptide hybrids in an effort to direct self-assembly and prepare supramolecular hierarchical architectures (Table 1). This section describes the design of diverse supramolecules based on silk proteins.

\section{Polypeptide/Peptide Design Inspired by Silk Proteins Pure Silk-Like Polypeptides with a Lower Molecular Weight}

Recombinant forms of the major native ampullate dragline spidroin 1-like proteins, with a molecular weight range of 250-320 kDa, have been successfully overexpressed in the host Escherichia coli BL21 (DE3), and strong fibers have been fabricated using these synthesized proteins (Xia et al., 2010). However, the synthesis of silk-like proteins comparable in size to the native silk protein still poses significant challenges to many material research groups. The most famous spider silk protein, the dragline silk protein of $A$. diadematus fibroin and $N$. clavipes fibroin, has received its fame through intensive investigations and recombinant genetic engineering redesign. Spider dragline silk proteins are great models and guides for the design of novel polypeptide. The spider dragline silk of $N$. clavipes contains at least two proteins: the major ampullate dragline spidroin 1 (MaSp1) and the major ampullate dragline spidroin 2 (MaSp2). The spider dragline silk of $A$. diadematus also contains two major proteins: A. diadematus fibroins 3 and 4 (ADF-3 and ADF-4). These dragline spidroins are composed of two alternating peptide motifs: a crystalline [An or (GA)n] motif and a less crystalline (GGX or GPGXX) motif (Scheibel, 2004). The An and (GA)n motifs form $\beta$-sheet crystal structures to provide a high tensile strength and stiffness in the dragline silk. On the other hand, the GPGGX motifs form type II $\beta$-turn structures, and the GGX motif forms a $3_{1}$-helix, both of which convey extensibility to the dragline fiber (Scheibel, 2004; Tokareva et al., 2013). With this understanding of the interplay between the sequence and the secondary structure 


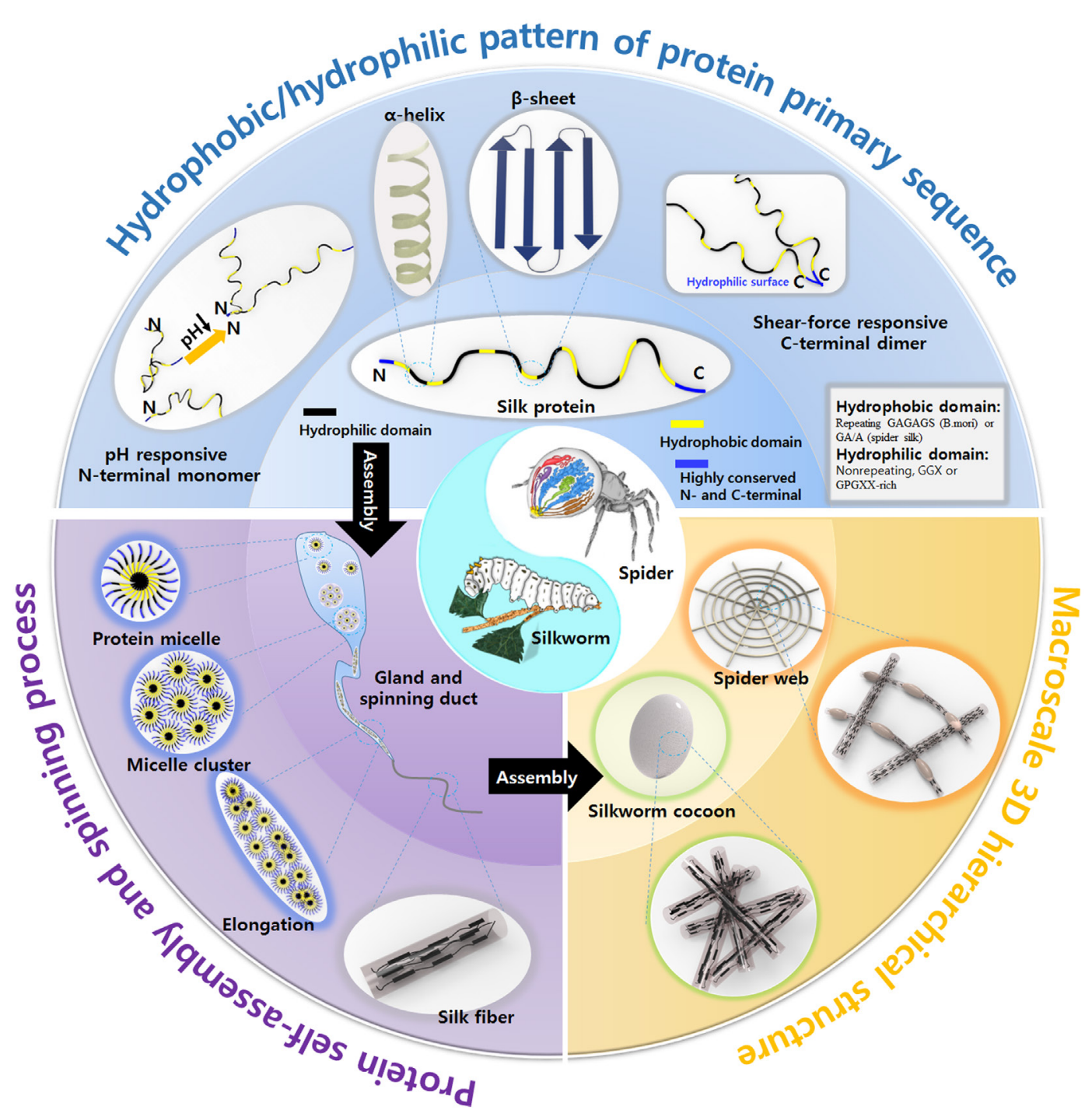

FIGURE 1 | Overview the inherent properties of natural silks produced by silkworm and spider, including the structural motif pattern of protein primary sequence, unique spinning process, and macroscale 3D hierarchical structure. Spider image: reprinted with permission from Kang et al. (2011). Copyright 2011 Nature Publishing Group; Silkworm image: reprinted with permission from Chae et al. (2013). Copyright 2013 John Wiley and Sons.

properties, scientists have designed a series of spider silk-like polypeptides and peptides. The repeating motifs of ADF-3 and ADF-4 have been multimerized through recombinant DNA technology to obtain an ADF-like polypeptide (Huemmerich et al., 2004; Rammensee et al., 2006, 2008). The ADF-4-like polypeptide (called C16) with a molecular mass of $48 \mathrm{kDa}$ self-assembles into nanofibers in the presence of methanol. These nanofibers then further self-assemble to form a hydrogel (Rammensee et al., 2006). The same artificial polypeptide may be used to fabricate both microspheres and nanofibers by inducing self-assembly in the presence of a kosmotropic agent, such as potassium phosphate (Slotta et al., 2007). C16 also can self-assemble to form a thin film at an oil-water interface and encapsulate active agents inside a water phase (Hermanson et al., 2007). C16 adsorbs onto oil-water interface, and a film or microcapsule is formed rapidly due to a secondary structure transition undertaken by $\mathrm{C} 16$ at the interface (Figure 2A). These encapsulates can be released rapidly by digesting the $\mathrm{C} 16$ film with proteinase $\mathrm{K}$ (Hermanson et al., 2007). The ADF-3-like polypeptide and ADF-3's conserved non-repeating region at the $\mathrm{C}$-terminus has been recombinantly produced in an effort to probe the natural spider spinning process (Rammensee et al., 2008; Hagn et al., 2010).

\section{Silk Peptide Fusion with Other Functional Peptide Sequences}

Spider silk proteins have been fused with a variety of functional peptides, including the integrin-binding motif RGD (LealEgana and Scheibel, 2012; Leal-Egaña et al., 2012; Wohlrab et al., 2012), the cell-binding peptide IKVAV (Graf et al., 1987; Grant et al., 1989; Widhe et al., 2013), antimicrobial peptides 
TABLE 1 | Summary of the self-assembled nano/microstructures based on silk peptide sequence and their potential applications.

\begin{tabular}{|c|c|c|c|c|c|}
\hline & Sequence $^{\mathrm{a}-\mathrm{c}}$ & Structures & Media & $\begin{array}{l}\text { Potential } \\
\text { applications }\end{array}$ & Reference \\
\hline \multirow[t]{21}{*}{$\begin{array}{l}\text { Peptide/ } \\
\text { polypeptide }\end{array}$} & $\begin{array}{l}\text { (GSSAAAAAAAASGPGGYGPENQGPSGPG } \\
\text { GYGPGGP) })_{16}\end{array}$ & Nanofiber/hydrogel & Methanol/water & Tissue engineering & Rammensee et al. (2006) \\
\hline & (GSSAAAAAAAASGPGGYGPENQGPSGPG & Sphere & Potassium & Drug delivery & Slotta et al. (2007) \\
\hline & GYGPGGP) ${ }_{16}$ & & phosphate & & \\
\hline & (GSSAAAAAAAASGPGGYGPENQGPSG & Capsule & Water/oil interface & Encapsulation & Hermanson et al. (2007) \\
\hline & PGGYGPGGP) $_{16}$ & & & & \\
\hline & (SGRGGLGGQGAGAAAAAGGAGQG & Nanoparticle & Water & Gene delivery & Numata and Kaplan \\
\hline & GYGGLGSQGT) $)_{6}-30 K-p p T G 1$ & & & & $(2010)$ \\
\hline & (SGRGGLGGQGAGAAAAAGGAGQGGYG & Nanoparticle & Water & Gene delivery & Numata et al. (2011) \\
\hline & GLGSQGT) $)_{6}-30 K-C G K R K$ or $-(C G K R K)_{2}$ & & & & \\
\hline & {$\left[(G \vee G \vee P)_{4}(G Y G V P)(G \vee G V P)_{3}(G A G A G S)\right]_{14}$} & Nanoparticle & Water & Controlled release & $\begin{array}{l}\text { Xia et al. (2011) and Xia } \\
\text { et al. (2014) }\end{array}$ \\
\hline & {$\left[(G \vee G \vee P)_{4}(G Y G V P)(G \vee G V P)_{3}(G A G A G S)_{2}\right]_{12}$} & $\begin{array}{l}\text { Nanoparticle/ } \\
\text { nanofiber }\end{array}$ & Water & Controlled release & $\begin{array}{l}\text { Xia et al. (2011) and Xia } \\
\text { et al. (2014) }\end{array}$ \\
\hline & {$\left[(G \vee G V P)_{4}(G Y G V P)(G \vee G V P)_{3}(G A G A G S)_{4}\right]_{9}$} & $\begin{array}{l}\text { Nanoparticle/ } \\
\text { nanofiber }\end{array}$ & Water & Controlled release & $\begin{array}{l}\text { Xia et al. (2011) and Xia } \\
\text { et al. (2014) }\end{array}$ \\
\hline & $\mathrm{H}_{10}-\left[(\mathrm{GVGVP})_{4}(\mathrm{GGGVP})(\mathrm{GVGVP})_{3}(\mathrm{GAGAGS})_{4}\right]_{\mathrm{n}}=3,8,13,18$ & Micelle & Water & $\begin{array}{l}\text { Biosensor/drug } \\
\text { delivery }\end{array}$ & Lin et al. (2014) \\
\hline & (GAGSGAGAGS)[(GVGVP) ${ }_{4}($ GKGVP) & Injectable hydrogel & Water/in vivo & Gene delivery & Megeed et al. (2002) and \\
\hline & $\left.(G \vee G V P)_{3}(\text { GAGAGS })_{4}\right]_{12}(G \vee G V P)_{4}(G K G V P)$ & & & & Megeed et al. (2004) \\
\hline & $(\text { GVGVP) })_{3}(\text { GAGAGS })_{2}$ GAGA & & & & \\
\hline & 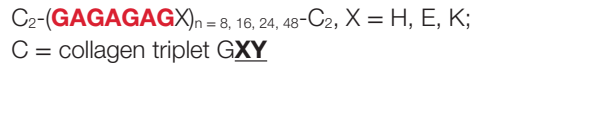 & $\begin{array}{l}\text { Micelle/nanofiber/ } \\
\text { nanotape/hydrogel }\end{array}$ & Water & $\begin{array}{l}\text { Target delivery/tissue } \\
\text { engineering }\end{array}$ & $\begin{array}{l}\text { Martens et al. (2009), } \\
\text { Beun et al. (2012), Beun } \\
\text { et al. (2014), and Golinska } \\
\text { et al. (2014) }\end{array}$ \\
\hline & $A_{n} K, n=3,4,6,8,9,10$ & $\begin{array}{l}\text { Nanotube/nematic } \\
\text { lamellar/nanorod/ } \\
\text { nanofibril }\end{array}$ & Water & $\begin{array}{l}\text { Nanofabrication/ } \\
\text { protein misfolding } \\
\text { research/antibacterial } \\
\text { peptide }\end{array}$ & $\begin{array}{l}\text { von Maltzahn et al. } \\
\text { (2003), Bucak et al. } \\
\text { (2009), Qiu et al. (2009), } \\
\text { Wang et al. (2009), } \\
\text { Castelletto et al. (2010), } \\
\text { Chen et al. (2010), Cenker } \\
\text { et al. (2011), and Cenker } \\
\text { et al. (2014) }\end{array}$ \\
\hline & $\mathrm{A}_{6} \mathrm{D}$ & Nanotube/nanofibril & Water & $\begin{array}{l}\text { Protein misfolding } \\
\text { research/membrane } \\
\text { proteins stabilization }\end{array}$ & $\begin{array}{l}\text { Vauthey et al. (2002) and } \\
\text { Zhao et al. (2006) }\end{array}$ \\
\hline & $\mathbf{A}_{6} \mathrm{H}$ & $\begin{array}{l}\text { Nanotape/ } \\
\text { nanosheet }\end{array}$ & $\begin{array}{l}\text { Acidic/neutral } \mathrm{ZnCl}_{2} \\
\text { aqueous solutions }\end{array}$ & lons chelation & Castelletto et al. (2014) \\
\hline & $\mathrm{A}_{12} \mathrm{R}_{2}$ & Twisted fibrils & Water & Nanobiotechnology & Hamley et al. (2013) \\
\hline \multirow[t]{6}{*}{$\begin{array}{l}\text { Peptide- } \\
\text { polymer hybrid }\end{array}$} & $\mathrm{PEG}-\left[(\mathbf{A G})_{3} \mathrm{EG}\right]_{\mathrm{n}}-\mathrm{PEG}, \mathrm{N}=10$ or 20 & Fibril/gel & $\begin{array}{l}\text { Formic acid/ } \\
\text { methanol }\end{array}$ & Nanofabrication & $\begin{array}{l}\text { Smeenk et al. (2005) and } \\
\text { Smeenk et al. (2006) }\end{array}$ \\
\hline & $\left(P I_{n}-\mathbf{A}_{5}-\right.$ spacer- $\left.\mathbf{A}_{5}\right) \mathrm{m}, \mathrm{n}=31$ or 72 & Micelle & $\begin{array}{l}\text { Chloroform/2- } \\
\text { chloroethanol }\end{array}$ & Nanofabrication & Zhou et al. (2006) \\
\hline & $\mathrm{Ax}-\left(\mathrm{O}-\mathrm{CH}_{2}-\mathrm{CH}_{2}\right)-\mathrm{Ax}_{\mathrm{x}}-\mathrm{PEG}, \mathrm{X}=4$ or 6 & Nanoparticle & Trifluoroethanol & Nanofabrication & $\begin{array}{l}\text { Rathore and Sogah } \\
(2001 \mathrm{a}, \mathrm{b})\end{array}$ \\
\hline & $(\alpha)$ tetrathiophene- $(\mathbf{G A})_{3} /(\mathbf{G A})_{3}-(\alpha)$ tetrathiophene- $(\mathbf{G A})_{3}$ & Bilayer/fibril & $\begin{array}{l}\text { Dichloromethane/ } \\
\text { graphite surface }\end{array}$ & Nanoelectronics & Gus'kova et al. (2008) \\
\hline & Poly(isobutylene)- $\mathbf{A}_{\mathbf{n}} / \mathbf{A}_{\mathbf{n}}$-Poly(isobutylene)- $\mathbf{A}_{n}, \mathrm{n}=0-5$ & $\begin{array}{l}\text { Tape/nanofibril/ } \\
\text { interpenetrating } \\
\text { supramolecular } \\
\text { network }\end{array}$ & $\begin{array}{l}\text { Tetrachlorethane/ } \\
\text { chloroform }\end{array}$ & Elastomer & Croisier et al. (2014) \\
\hline & HSNGLPLGGGSEEEAAAWW(K)-CO(CH 2$)_{10} \mathrm{CH}_{3}$ & Nanofiber/hydrogel & & $\begin{array}{l}\text { Drug delivery/tissue } \\
\text { engineering }\end{array}$ & Shah et al. (2010) \\
\hline
\end{tabular}

${ }^{a}$ Red-bolds denote silk protein sequence.

${ }^{b}$ Single amino acid abbreviations used: A, Ala; C, Cys; D, Asp; E, Glu; G, Gly; H, His; K, Lys; L, Leu; M, Met; N, Asn; P, Pro; Q, Gln; R, Arg; S, Ser; and V, Val.

${ }^{c}$ Non-functional amino acid sequence domains at $N$ - and $C$-terminus are omitted for simplicity.

GXY : $X$ and Y positions can be any residue but are frequently occupied by Pro and Hyp.

(Gomes et al., 2011), silver ion-binding peptides (Currie et al., 2011), and silica-binding peptides (Wong Po Foo et al., 2006). These hybrids may be applied as a film and coating material to improve the surface properties of biomaterials. Silk protein-based biomaterials prepared via top-down methods have been reviewed extensively elsewhere. Here, we discuss supramolecular assemblies formed by silk-functional peptide fusions. Numata and Kaplan (2010) reported the use of a silk-polylysine-ppTG1 

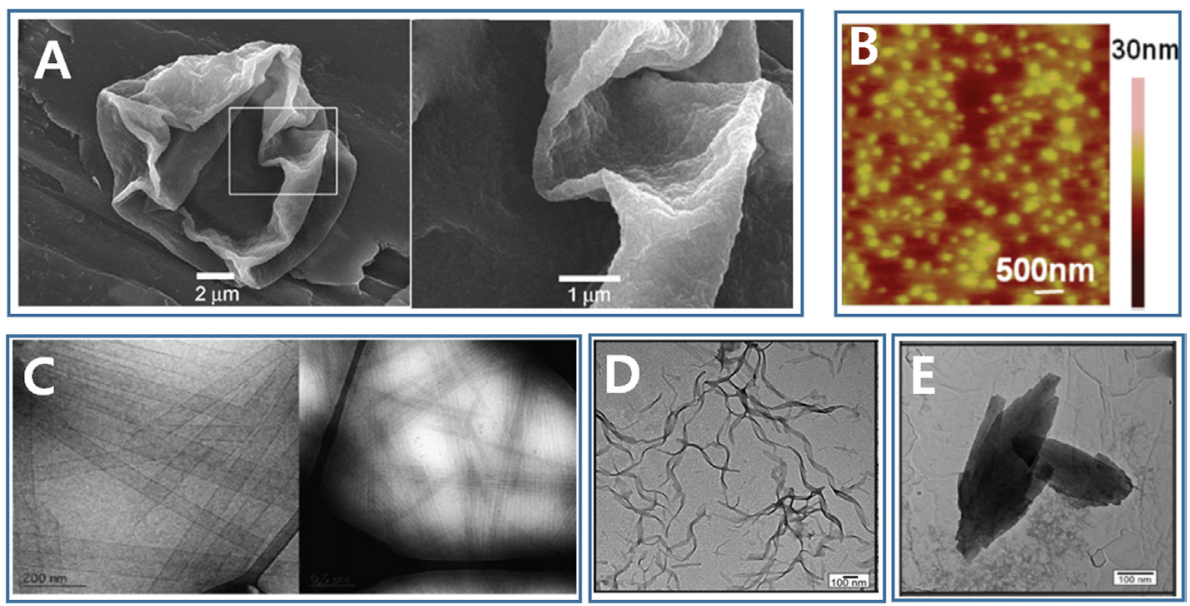

FIGURE 2 | Nano/microstructures formed through molecular self-assembly of silk-based peptide and peptide/polymer hybrid. (A) Microcapsule [Reprinted with permission from Hermanson et al. (2007). Copyright 2007 John Wiley and Sons]. (B) Nanoparticle [Reprinted with permission from Numata and Kaplan (2010). Copyright 2010 American Chemical Society]. (C) Nanotube [Reprinted with permission from Cenker et al. (2011). Copyright 2011 Royal Society of Chemistry]. (D) Nanotape [Reprinted with permission from Castelletto et al. (2014). Copyright 2014 American Chemical Society]. (E) Nanosheet [Reprinted with permission from Castelletto et al. (2014). Copyright 2014 American Chemical Society].

fusion polypeptide as gene carrier. The consensus repeat sequence (SGRGGLGGQGAGAAAAAGGAGQGGYGGLGSQGT) of the native MaSp1 was chosen to prepare the fusion polypeptide (silk6mer-30lysine-ppTG1), with 6 contiguous copies of MaSp1 repeating domains, 30 lysines, and a ppTG1 peptide domain fused at its C-terminus. The silk-polylysine-ppTG1 protein trapped pDNA to form micelle-like nanoparticles with an average hydrodynamic diameter of $99 \mathrm{~nm}$ (Figure 2B), and this structure displayed a high transfection efficiency (Numata and Kaplan, 2010). The profile of the released genes could be further regulated by selectively controlling the $\beta$-sheet content of the silk domains in the gene carrier nanoparticle. The same group also fused this basic silk-30 lysine polypeptide to tumor-homing peptides to form gene delivery nanoparticles $150-250 \mathrm{~nm}$ in size. This gene delivery system showed significant target specificity to tumor cells (Numata et al., 2011). Silk crystalline protein domains have been genetically fused with other fibrous protein domains, including the elastin repeating hydrophobic domain (GVGVP) and the collagen repeating triplet domain. Silk-elastin polypeptides (SELPs) consist of silkworm silk protein domains (GAGAGS) and environmentally sensitive elastin domains (GXGVP, X could be any amino acid other than proline). SELPs undergo a two-step selfassembly process in aqueous solutions (Xia et al., 2011). The first assembly step is driven by the silk domains. Because the elastin domains are more hydrophilic below their transition temperature than the silk domains, the silk domains drive SELPs to selfassemble into micelles through hydrophobic associations among the silk domains in water. The second self-assembly step is driven by the elastin domains at higher temperatures (Cheng et al., 2013, 2014a). In the second step, the SELP micelles associate to form higher-order nanostructures, including hydrogels and nanofibers (Xia et al., 2011). These SELPs may be used to encapsulate the hydrophobic antitumor drug doxorubicin into the core of the SELP nanoparticles to promote significant uptake by the cells (Xia et al., 2014). SELPs are good candidates for use in the design of thermo-responsive photonic/electronic systems (Lin et al., 2014). Lin et al. (2014) designed a series of SELPs with a polyhistidine tag at the N-terminus, and these SELPs were shown to bind to the surfaces of nickel chelate nitrilotriacetate-functionalized gold nanoparticles through the nickel affinity of the polyhistidine tag. SELPs drive the gold nanoparticles to aggregate through hydrophobic interactions among the elastin domains at high temperatures, leading to a red shift in the Au nanoparticle surface plasmon resonance. The SELP-Au nanoparticle system may be used as a self-adaptive plasmonic nanodevice for biosensing. Megeed et al. (2002, 2004) designed SELPs-based injectable hydrogels for gene delivery applications. An SELP-47K was designed based on four silk domains and eight elastin domains. A large number of lysine amino acids were coded into elastin domains, and negatively charged DNA bound to the positively charged lysine groups to form a DNA/SELP complex. The SELP/DNA complex formed a hydrogel at body temperature and could be used for injectable gene delivery. Cohen Stuart's group designed a series of stimuliresponsive silk collagen-like polypeptides $\left(\mathrm{C}_{2} \mathrm{~S}_{n}^{\mathrm{X}} \mathrm{C}_{2}\right.$ composed of a middle silkworm silk-like peptide domain (S) flanked by two collagen-like peptide domains (C) (Martens et al., 2009; Beun et al., 2012, 2014; Golinska et al., 2014). The middle silk domains consisted of the sequence GAGAGAGX, and $\mathrm{pH}$-responsive amino residues were introduced at position $\mathrm{X}$, resulting in the $\mathrm{pH}$-triggered self-assembly of $\mathrm{C}_{2} \mathrm{~S}_{\mathrm{n}}^{\mathrm{X}} \mathrm{C}_{2}$ into various nanomaterials (micelles, nanofibers, nanotapes, and hydrogels). The $\mathrm{C}_{2} \mathrm{~S}_{\mathrm{n}}^{\mathrm{X}} \mathrm{C}_{2}$ sequence was shown to mimic the properties of natural collagen, lending its potential utility in tissue engineering applications.

\section{Small Surfactant-Like Peptide Based on the Silk Protein Domain}

The crystalline An domains of the native silk proteins drive self-assembly via hydrophobic interactions and stabilize the 
assembly via inter- or intramolecular hydrogen bonding. This sequence has been attached to a head group bearing one or more charged amino acids [e.g., histidine $(\mathrm{H})$, arginine $(\mathrm{R})$, lysine $(\mathrm{K})$, or aspartic acid (D)] to prepare surfactant-like small peptides (SLSPs). SLSPs have properties very similar to those observed in biological surfactant molecules and show particular promise in bionanotechnology and biomedicine applications. A variety of silk domain-based SLSPs have been reported, including $\mathrm{A}_{6} \mathrm{H}$, $A_{6} D, A n K$, and $A_{12} R_{2}$, and these SLSPs undergo self-assembly to form nanostructures in an aqueous environment.

The $A_{n} K$ family is the most extensively studied SLSP, where $n$ may be $3,4,6,8,9$, or 10 . The self-assembly of $A_{n} K$ is concentration dependent. $\mathrm{A}_{6} \mathrm{~K}$ was found to self-assemble above a critical concentration in aqueous solutions and form hollow nanotubes with a radius of $26 \mathrm{~nm}$ (Figure $2 \mathrm{C}$ ), followed by a transition to a nematic lamellar phase with increasing peptide concentration (Bucak et al., 2009; Castelletto et al., 2010; Cenker et al., 2011). $\mathrm{A}_{4} \mathrm{~K}$ could not self-assemble to form nanostructures. On the other hand, $\mathrm{A}_{8} \mathrm{~K}$ and $\mathrm{A}_{10} \mathrm{~K}$ self-assembled to form thin rod-like aggregates, possibly due to the increased hydrophobicity as more alanine amino residues were added (Cenker et al., 2014). The $A_{n} K$ peptides designed by Zhang et al. (von Maltzahn et al., 2003) and later by Zhao et al. (Qiu et al., 2009; Wang et al., 2009) were capped either at both ends or at the N-terminus. These peptides formed nanofibrils other than nanotubes, because the caps influenced the hydrophobicity of the peptides. The $\mathrm{A}_{6} \mathrm{D}, \mathrm{A}_{6} \mathrm{H}$, and $\mathrm{A}_{12} \mathrm{R}_{2}$ constructs are self-assembled to form various nanostructures, including nanotubes, nanovesicles, nanotapes (Figure 2D), nanosheets (Figure 2E), or twisted fibrils (Vauthey et al., 2002; Zhao et al., 2006; Hamley et al., 2013; Castelletto et al., 2014).

\section{Polymer-Peptide Hybrids Inspired by Silk Proteins}

The incorporation of silk's $\beta$-sheet-forming peptide domain (GA)n or (A)n to form a synthetic polymer offers an effective approach to design supramolecular materials via self-assembly. Smeenk et al. $(2005,2006)$ reported the development of a triblock polymer consisting of a central silk $\beta$-sheet domain $\left[(\mathrm{AG})_{3} \mathrm{EG}\right]$ $\mathrm{n}$ with one PEG block at both its $\mathrm{N}$ - and $\mathrm{C}$-termini. The central silk $\beta$-sheet domain was overexpressed in E. coli and purified via nickel-nitrilotriacetate (Ni-NTA) affinity chromatography. One cysteine amino residue at each peptide terminus was used to selectively alkylate the maleimide-functionalized PEG. The PEG blocks prevented the central silk $\beta$-sheet domains from forming random macroscopic aggregates. Instead, the central $\beta$-sheet domains stacked together in an orderly fashion to form well-defined fibrils (Smeenk et al., 2005).

Zhou et al. (2006) reported a series of silk-like multiblock peptide-polymer hybrids containing $\mathrm{A}_{5}$ blocks and polyisoprene oligomers (PI). The PI oligomer improved the solubility of the hybrid polymer, just as glycine-rich domains do in natural silk proteins. The $\mathrm{A}_{5}$ blocks directed the hybrid polymer to selfassemble into micelles through the formation of an antiparallel $\beta$-sheet core in the presence of chloroform or 2-chloroethanol. A similar design concept was applied by Rathore et al., who replaced amorphous domains of the silk proteins with PEG. The remaining $\beta$-sheet-forming domain of the silk proteins were then included in the synthesized PEG-peptide copolymer, which self-assembled to form nanostructures (Rathore and Sogah, 2001a,b).

The GAGAG pentapeptide was conjugated to tetrathiophene to form diblock or triblock peptide/polymer hybrids that selfassembled into supramolecular structures at the graphite surface and in organic solvents due to $\beta$-sheet formation among the peptide blocks (Gus'kova et al., 2008). The thiophene blocks further stabilized the supramolecule through the formation of $\pi-\pi$ stacks, which conveyed conductivity to the supramolecular structures (Gus'kova et al., 2008).

Croisier et al. (2014) synthesized a series of peptide/ poly(isobutylene) hybrid elastomers. In these hybrids, silk peptides were conjugated to one terminus or both termini of an poly(isobutylene) unit to form a diblock hybrid (monofunctional hybrid M) or a triblock hybrid (difunctional hybrid D). The silk peptide domains directed $\mathrm{M}$ and $\mathrm{D}$ to self-assemble into various nanostructures. The length of the silk peptide domain determined the morphology of the nanostructures formed through self-assembly. Both the $\mathrm{M}$ and $\mathrm{D}$ units comprising short peptide domains formed small aggregates. As the length of the peptide domain increased, single $\beta$-sheet tapes and stacked nanofibrils formed. Mixing $\mathrm{M}$ and $\mathrm{D}$ together gave rise to inherently reinforced thermoplastic elastomers and interpenetrating supramolecular networks (Croisier et al., 2014).

Self-assembly in the various silk-inspired peptide-polymer hybrids mentioned above required an organic solvent environment, and hydrogen bonds formed among the silk peptides to strengthen and direct the self-assembly process. Stupp's group described the use of a series of well-known diblock polymers, the peptide amphiphiles (PA), consisting of a peptide segment and a more hydrophobic alkyl tail that self-assemble to form supramolecular nanofibers in an aqueous solution (Hartgerink et al., 2001, 2002; Claussen et al., 2003; Behanna et al., 2005; Shah et al., 2010). The silk GA domains were incorporated into the PAs to provide stability to the nanofibers by forming $\beta$-sheets in the fibers (Shah et al., 2010). The PAs provide a powerful tool for drug delivery and tissue engineering.

\section{NOVEL SPINNING PROCESSES AND MICROPLATFORMS INSPIRED BY NATURE}

The outstanding mechanical properties of silk fibers originate from both the silk protein's unique primary sequence and the distinctive spinning process used during fiber fabrication. The success of spider silk spinning lies in the various silk proteins produced in its multiple glands, the extensional field formed inside its tapered duct, and the post-spin drawing action of the spider's legs. This section discusses a variety of spinning methods using microfluidic platforms that provide excellent quality fibers through the control over multiphase flows in small amounts of liquid.

\section{Spinning and the Mimicking of Multiple Glands}

Individual spiders can spin a variety of silks. For example, the female orb-weaving spiders spin up to seven different types of 
silks to meet different needs using seven different glands. The multigland design of the orb-weaving spider was implemented by our group to continuously spin fibers with spatiotemporal variations in chemical composition and morphology using polydimethylsiloxane (PDMS) microfluidic chips (Figure 3A) (Kang et al., 2011). The microfluidic chip consisted of several individually controllable inlets that mimicked the multiple glands of the spider. Switching among these inlets was precisely controlled using a computer-controlled pneumatic valve that enabled the preparation of fibers with spatially organized morphologies and compositions. Multiple compositions and topographies, including gas microbubbles, nanoporous spindle knots, and a variety of cells, could be coded into a single fiber (Kang et al., 2011). Similar design concepts were implemented by Qin et al. to prepare hybrid microfibers with bamboo-like or pearl-like morphologies by combining the droplet microfluidic technique with microfluidic wet spinning (Yu et al., 2014). Hydrophobic droplets containing polymer microspheres or multicellular spheroids were encapsulated in a continuous alginate hydrophilic phase using " $T$ " junction channels. The Gu's group replaced the PDMS microfluidic chip and mimicked spider's multiple glands using a capillary coaxial microfluidic device (Cheng et al., 2014b). Multiple tapered barrel capillaries were coaxially inserted into a single collection capillary to fabricate two- to six-compartment calcium alginate microfibers. Capillaries have been inserted into a single collection capillary in a hierarchical manner to prepare multilayers microfibers. Different cells could then be encapsulated into different alginate compartments or layers.

Although silkworms, such as B. mori, have only two identical glands, three partitions are present in each gland. Silk fibroins are secreted in the posterior gland and transported to the middle gland, where sericins are secreted. In the middle gland, the silk fibroins phase separate to form microscale micelle globules, which improve silk fibroin alignment under physical shear stress (Jin and Kaplan, 2003). A PDMS platform was used to simulate the silkworm spinning process, and a series of micro/nanometerscale alginate fibers with highly aligned alginate polymers were fabricated by inducing alginate phase separation inside the PDMS channel (Chae et al., 2013). Isopropyl alcohol (IPA) in a sheath flow diffused into the alginate core flow, leading to alginate phase separation to form small alginate particles. The shear forces in the microfluidic channels aligned these alginate particles to form highly crystallized alginate fibers (Chae et al., 2013).

\section{Spinning via a Tapered Duct-Based Elongational Mechanism}

The outstanding mechanical properties of spider silk are closely related to the spider's tapered spinning duct, which applies an elongational field that orients the short spidroin filaments along the direction of the elongational field (Vollrath and Knight, 2001). Capillaries with tapered orifices provide a simple approach to create elongational flows. This approach has been used to align small nanofibrils and form long microfibers. We reported the first example of a microfluidic spinning process using a microfluidic chip that integrated a tapered glass capillary (Jeong et al., 2004). Diverse hydrogel-based solids and hollow fibers were fabricated using variations on these chip designs (Shin et al., 2007; Hwang et al., 2008, 2009; Lee et al., 2009, 2010). Stupp's group used a tapered pipet to prepare noodle-like strings in which peptide amphiphile nanofibers aligned and were bundled along the longitudinal direction of the string (Zhang et al., 2010). The strings could be used to encapsulate cells and direct the orientations of the cells in a $3 \mathrm{D}$ environment. Human mesenchymal stem cells (hMSCs) were found to remain viable during the string preparation process. Both the cell bodies and filopodia were aligned along the peptide amphiphile nanofibers due to contact guidance by the oriented matrix (Zhang et al., 2010). Takeuchi's group designed a series of coaxial microfluidic glass capillaries with tapered orifices to control the assembly of diverse small structures under flow (Kiriya et al., 2012a,b; Hirayama et al., 2013; Onoe et al., 2013). In the elongational flow, small nanofibers formed the core flow and were oriented along the flow stream as the sheath flow velocity exceeded the core flow (Kiriya et al., 2012b). The elongational flow overcame the hydrophobic/hydrophilic interactions and oriented the lipid-type monomers to form meter-long fibers. The fibers were then used as templates to synthesize poly(aniline) conductive nanofibers with a high conductivity and potential utility as sensor materials (Kiriya et al., 2012a). Fast sheath flows and slower core flows can create an elongational field and such fields have been used to induce alignment of carbon nanotubes (CNTs) (Davis et al., 2009). Single-wall CNTs in pure chlorosulfonic acid at a concentration of 8.5 vol\% were spun into a faster-flowing $96 \%$ sulfuric acid sheath flow to form CNT fibers uniformly composed of oriented CNT fibrils. These fibers showed great mechanical properties and a high conductivity (Davis et al., 2009).

Our group has fabricated PDMS-only cylindrical coaxial flow channels with a tapered orifice to mimic the spider's tapered spinning duct (Figure 3B) (Kang et al., 2010, 2011). The PDMS-based mold was prepared using soft lithography techniques. A thin PDMS membrane was subsequently bonded to the PDMS base mold, and a negative pressure was applied to form a concave hemicylindrical channel. The hemicylindrical channel was replicated with SU-8, and a convex hemicylindrical SU-8 master was obtained. The convex hemicylindrical SU-8 master was used to prepare a concave hemicylindrical PDMS channel. The PDMS chip used to prepare the fibers was constructed by aligning and bonding two concave hemicylindrical PDMS channels using oxygen plasma treatment (Kang et al., 2010, 2011). This PDMS chip was used to continuously prepare monodisperse microfibers for cell encapsulation and tissue engineering (Kang et al., 2012, 2014; Jun et al., 2013, 2014a,b).

\section{Post-Spin Drawing Process}

During the natural silk spinning process, the fibers are drawn out of the spinning duct either using the legs of the spider or through the "figure eight" movements of the silkworm head (Omenetto and Kaplan, 2010). This drawing process orients the silk proteins along the longitudinal axis of the fibers and improves the fibers' mechanical properties. The post-spin drawing process used by silkworms and spiders has been replicated in conventional processes to improve the mechanical properties of the artificial 

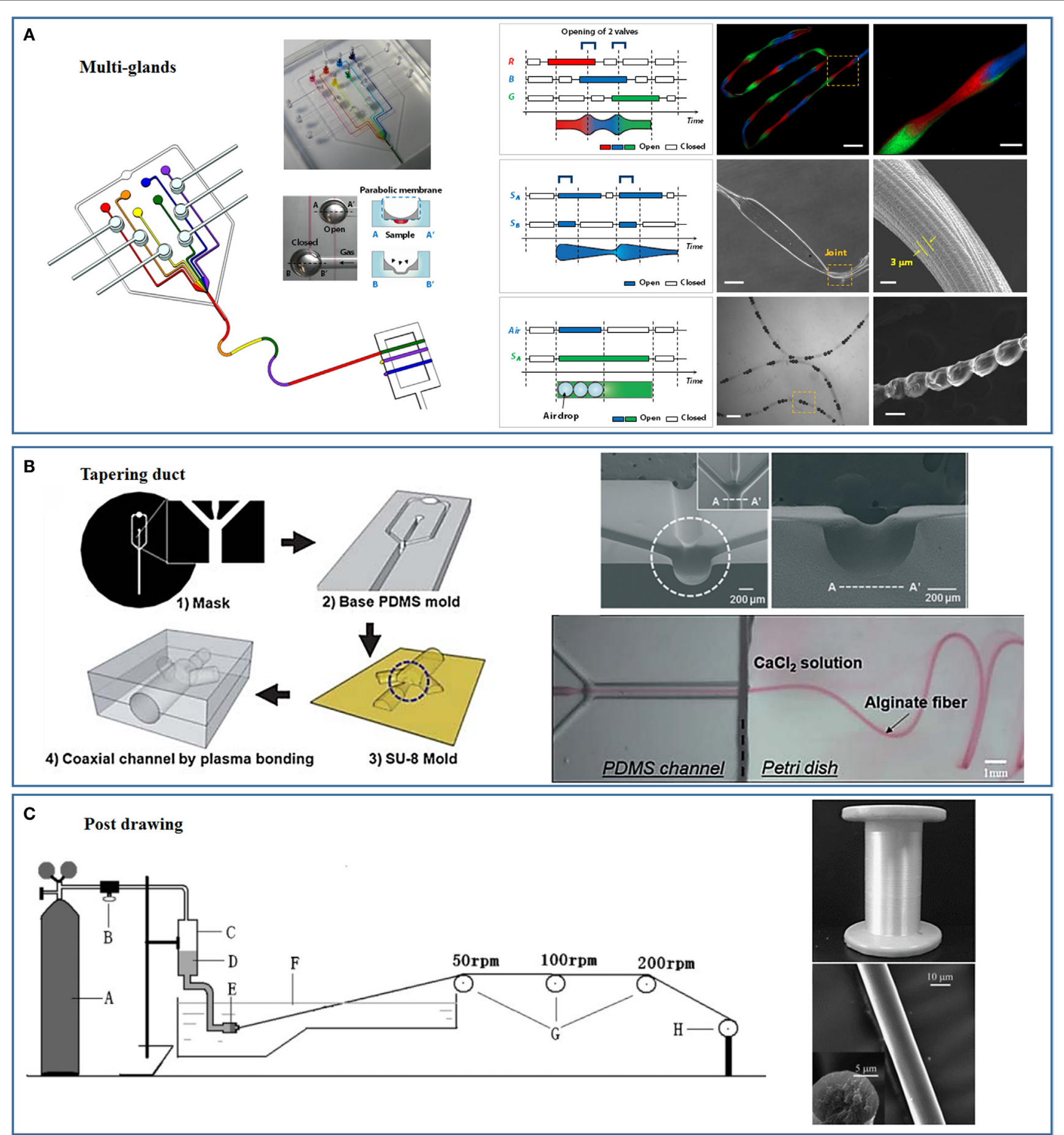

FIGURE 3 | Novel spinning processes and microplatforms inspired by nature. (A) Multi-glands mimicking microfluidic chip and the as-spun hierarchical artificial microfibers [reprinted with permission from Kang et al. (2011). Copyright 2011 Nature Publishing Group]. (B) Tapering duct mimicking microfluidic chip [reprinted with permission from Kang et al. (2010). Copyright 2010 Royal Society of Chemistry; reprinted with permission from Jun et al. (2013). Copyright 2013 Elsevier]. (C) Strong fibers prepared through mimicking the post-drawing process of natural spinning [reprinted with permission from Zhou et al. (2009). Copyright 2009 John Wiley and Sons].

fibers. Chen et al. prepared strong artificial silk fibroin fibers by continuously drawing the fibers through a series of plastic rollers with different rotating speeds, the post-spun drawn fibers showed mechanical properties comparable to those of the natural silkworm silk fibers (Figure 3C) (Zhou et al., 2009; Yan et al., 2010). The same spinning process was applied by Chen's group 
to a spinning dope composed of a silk fibroin-CNT composite to prepare strong artificial fibers with breaking energies comparable to that of the spider dragline silk fibers (Fang et al., 2015). Lewis's group used post-spin drawing to prepare strong artificial spider silk fibers (An et al., 2011). Post-spin drawing significantly increased the fiber tensile strength due to the improved protein molecule rearrangement and $\beta$-sheet formation in the polyalanine region (An et al., 2011). We recently successfully spun microfibers using silk fibroin and alginate, and the mechanical properties of the fibers were significantly enhanced by the post-spin drawing process (unpublished data).

\section{DEVELOPMENT OF NEW SMART MATERIALS AND APPLICATIONS INSPIRED BY COMPLEX HIERARCHICAL ARCHITECTURES CONSTRUCTED BY SILKWORM AND SPIDER}

The advanced functions of most natural materials rely on the complex hierarchical structures of the materials (Sanchez et al., 2005). Recent studies have revealed that the strength of silk fibers also relies on its hierarchical structure (Cranford et al., 2012; Koski et al., 2013; Qin and Buehler, 2013; Silva and Rech, 2013; Qin et al., 2015). The structure of a spider's web is hierarchical in two aspects: the protein secondary structure inside a single silk fiber is hierarchical and the geometric structure of the whole web is hierarchical. Together, these structures contribute to the outstanding properties of natural spider webs (Cranford et al., 2012; Qin et al., 2015). The hierarchical protein secondary structure (semi-amorphous and $\beta$-sheet nanocrystals) in a single spider silk fiber leads to non-linear stress-strain behaviors of the silk fiber, resulting in small web deformations under the application of an external force to a single fiber (Cranford et al., 2012). Orb web spiders produce up to seven different types of silk fibers using their different glands to weave a hierarchical web net, and any insects trapped in this thin fiber net have no chance of escape. The framework of the web is constructed using dragline silk produced by the major ampullate gland (MA gland). The capture spiral is jointly constructed by minor ampullate spidroin silk fibers produced in the minor ampullate gland (MI gland) and by flagelliform silk fibers produced in the flagelliform gland. The auxiliary spiral is first constructed using ampullate spidroin silk fibers to stabilize the emerging web structure and to serve as a template in support of the construction of the capture structure using the flagelliform silk fibers. The whole web structure is fixed by a gluey substance called attachment cement, which is produced in the piriform gland (Heim et al., 2010).

Spiders spin a variety of silk fibers to meet their different needs, such as prey capture, prey swathing, or egg protection. Although the silkworm B. mori produces only one type of silk fiber to meet its exclusive need for cocoon weaving as a defense mechanism, the single silkworm silk fibers and the cocoon are hierarchical structural materials. Silkworm silk fibers consist of a fibroin core and a sericin shell, and the cocoon wall is a multilayer hierarchical architecture randomly weaved using the silk fibers.

\section{Cocoon Silk's Core/Shell Composite Structure Has Inspired the Development of Strong Fibers}

Cocoon silk fibers consist of a fibroin core and a sericin coating layer. The sericin layer allows for the efficient transfer of an external loading force to the fibroin core and improves the mechanical properties of the silk fiber. Inspired by this core/shell design, Jiang's group enforced lotus fibers by applying a poly(vinyl alcohol) (PVA) coating layer (Figure 4A) (Wu et al., 2014). In addition to improving the mechanical properties, the PVA layers acted as a glue to hold the individual fibers together as a fiber bundle. The mechanical properties of the fibers were further improved by introducing cross-links through heat treatment and glutaraldehyde.

\section{Spider Silk-Inspired CNT-Based Fiber Design}

The outstanding mechanical properties of spider silk rely on the plentiful intra- and intermolecular hydrogen bonds among the structural proteins. These features suggested a simple approach to strengthening artificial fibers. CNTs are extremely stiff and strong nanomaterials and have been widely used in nanocomposites to improve the mechanical properties of the materials. Scientists and engineers believe that the best approach to fully utilizing the outstanding mechanical properties of CNTs is to spin them into continuous fibers on the macroscale (Ericson et al., 2004; Zhang et al., 2005; Peng et al., 2008). The continuous spinning of CNTs has remained challenging due to the atomically smooth surfaces and cylindrical profile of the CNTs, which provide a low shear load transfer and facilitate sliding among aligned CNTs (Kis et al., 2004; Peng et al., 2008). Inspired by the silk fibers, hydrogen bonding functional groups were introduced onto the pristine CNT surfaces to improve the shear load transfer and prepare continuous CNT fibers. In addition to small functional groups, such as $\mathrm{OH}, \mathrm{NH}_{\mathrm{n}}$ may be introduced onto the CNT surfaces to form bridging hydrogen bonds among CNTs. Ultra-short polymers may also be covalently conjugated to the CNT surfaces to create a microstructural environment similar to that present in natural spider silk. Naraghi et al. (2013) functionalized CNT bundles with poly(methyl methacrylate)-like oligomers using chemical vapor deposition methods (Figure 4B). The van der Waals interactions increased the shear strength of the bundle junctions by an order of magnitude compared to the shear strength of the pristine CNT bundles.

\section{Spider Silk Adhesion Glue}

The viscid fibers of web-weaving spiders are coated with glycoprotein-based glue droplets that facilitate prey capture (Figure 4C) (Opell and Hendricks, 2009, 2010; Sahni et al., 2010; Stellwagen et al., 2014). The properties of the glue droplets depend on the rate at which they are extended. The glue droplets act as a viscous material under rapid extension, for example, when snared by a fast-flying insect, or as a viscoelastic material under slow extension, for example, during the attempts by trapped prey to escape (Sahni et al., 2010). The adhesion of the spider's glue droplet is 

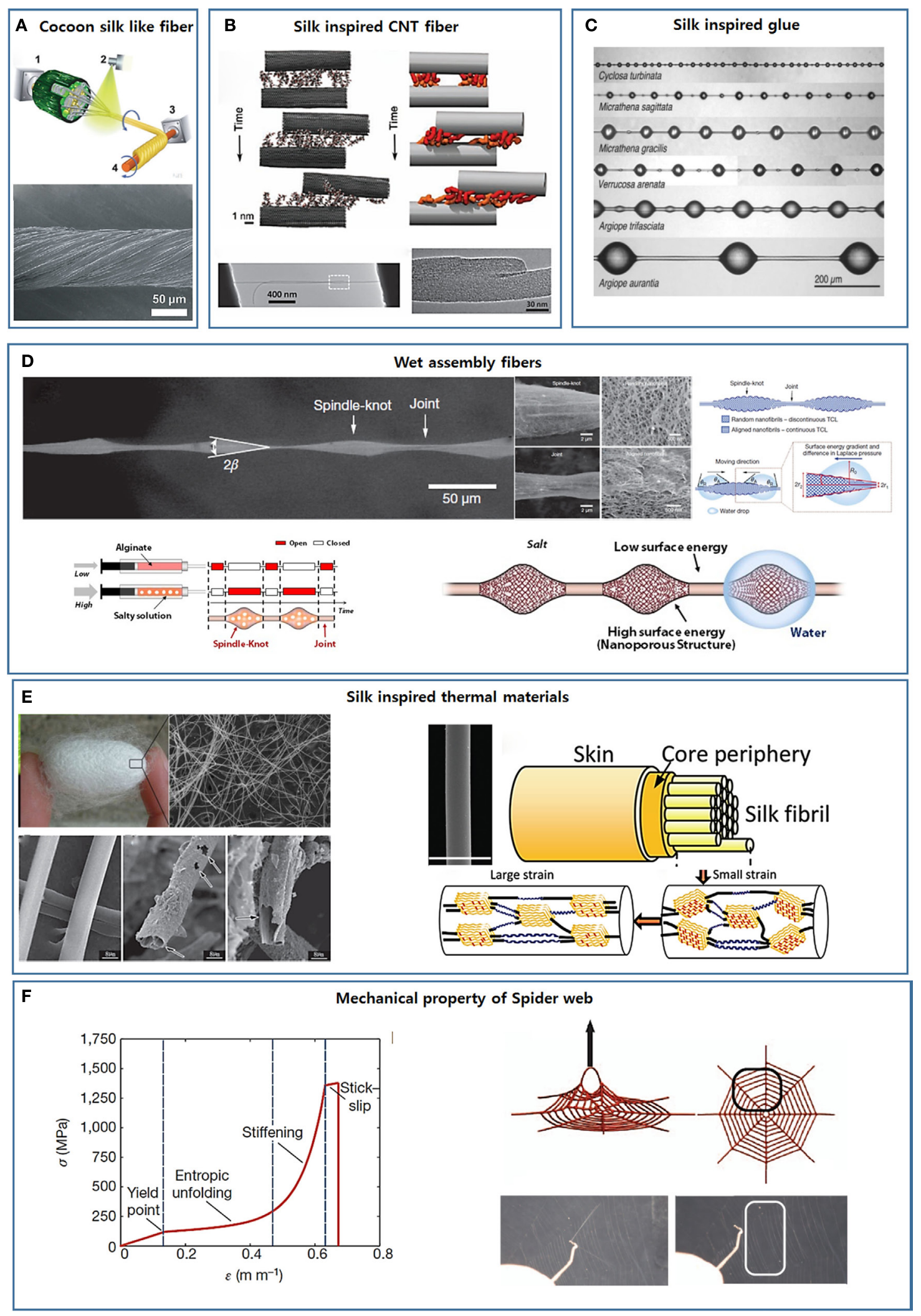

FIGURE 4 | Development of new smart materials by mimicking silk's complex hierarchical structure. 
FIGURE 4 | Continued

(A) Strong fibers developed mimicking cocoon silk's core/shell composite structure [reprinted with permission from Wu et al. (2014). Copyright 2014 John Wiley and Sons]. (B) Spider silk-inspired CNT-based fiber design [reprinted with permission from Naraghi et al. (2013). Copyright 2013 John Wiley and Sons]. (C) Glycoproteinbased glue droplets on spider silk [reprinted with permission from Opell and Hendricks (2009). Copyright 2009 Company of Biologists LTD]. (D) The hierarchical spindle knot-joint structure and the water-collecting properties of spider silks and artificial fibers [reprinted with permission from Zheng et al. (2010). Copyright 2010 Nature Publishing Group; reprinted with permission from Kang et al. (2011). Copyright 2011 Nature Publishing Group]. (E) Silk-inspired thermo-insulating and thermal conduction fibers [reprinted with permission from Wang et al. (2013). Copyright 2013 John Wiley and Sons; reprinted with permission from Huang et al. (2012). Copyright 2012 John Wiley and Sons]. (F) The non-linear mechanical characteristics of single silk fibers and the whole spider web [reprinted with permission from Cranford et al. (2012). Copyright 2012 Nature Publishing Group].

humidity responsive and increases with humidity. These properties are exactly opposite the properties displayed by synthetic adhesive systems. Although glue droplets appear to consist of a glycoprotein core and a viscous aqueous salt coating (Vollrath et al., 1990; Opell and Hendricks, 2009, 2010; Sahni et al., 2010; Stellwagen et al., 2014), an in-depth examination of the relationship between the chemical composition and the physical properties has not yet been conducted. Synthetic adhesive systems that display adhesion properties similar to those of spider silk have not yet been developed.

\section{Wet Assembly Fibers}

Aside from their outstanding mechanical properties, the watercollecting properties of spider silk can provide critical insights into the design of advanced materials (Wen et al., 2015). The water-collecting properties of silk result from the hierarchical spindle knot-joint structure formed during wetting in humid air (the upper panel in Figure 4D) (Zheng et al., 2010). Dry spider silk consists of puffs separated by joints. As the dry spider fibers encounter humid air, tiny water drops condense on the semitransparent puffs, and the puffs transform into periodic spindle knots as water condensation continues (Zheng et al., 2010). The spindle knots and joints are composed of random and aligned nanofibrils, respectively, which results in a surface energy gradient and a difference in the Laplace pressure between the spindle knots and the joints (Zheng et al., 2010). As a result, water continuously condenses and collects around the spindle knots.

Mechanistic insights gleaned from the water collection properties of spider silk have informed the development of spider silk-like artificial fibers based on a range of materials. Water collection properties similar to those of natural spider silk have been achieved. Zheng et al. prepared an artificial spider silk-like fiber using a simple dip-coating method. Uniform nylon fibers were immersed into a poly(methyl methacrylate)/ $N, N$ dimethylformamide ethanol (PMMA/DMF-EtOH) solution and then horizontally drawn out quickly (Zheng et al., 2010). After drying, the polymers formed periodic spindle knots on the surfaces of the nylon fibers (Zheng et al., 2010). The artificial polymer spindle knots were composed of random pores and artificial joints prepared from the stretched pores. The differences between the surface morphologies of the artificial spindle knots and joints gave rise to a surface energy gradient and difference in the Laplace pressure, yielding directional water collection around the spindle knots (Zheng et al., 2010).

Coaxial electrospinning methods offer a good approach to preparing spider silk-like fibers with periodic spindle knot/joint patterns (Tian et al., 2011; Dong et al., 2012). A viscous polystyrene
(PS) solution and a less viscous PMMA or poly(ethylene glycol) (PEG) solution were used as the inner and outer solutions, respectively, in a coaxial system. Under a high-voltage electric field, the inner PS solution spun to form a thin thread, whereas the outer PMMA or PEG solutions formed a thin film on the surface of the PS thread. The PMMA or PEG films broke to form periodic droplets and solidified into spindle knots on the surface of the PS thread (Tian et al., 2011; Dong et al., 2012). These electrospun fibers demonstrated capacities for directional water collection that resembled the corresponding capacity of natural spider silk fibers.

Our group used a multigland spider-mimicking microfluidic chip to prepare artificial spider silk-like fibers containing a spindle knot/joint pattern that directionally transported water toward the spindle knots (Kang et al., 2011). This microfluidic chip continuously created microfibers with strictly coded morphological and chemical features using a digital programmable flow controller. An alginate solution containing salt was injected into one of sample channels at a high flow rate to construct porous spindle knots (the lower left image in Figure 4D). An alginate solution without salt was injected into another sample channel at a low flow rate to construct joints (the lower left image in Figure 4D). As the salt leached from one flow to the other through diffusion, nanoporous spindle knots were generated. These spindle knots provided a higher surface energy than the joints. The tapered morphologies of the spindle knots generated a difference in the Laplace pressures of the spindle knots and joints. As expected, water droplets were directionally collected around the spindle knots under the combined action of the surface energy and the Laplace pressure differential (the lower right image in Figure 4D).

The relationship between directional water transport and differences in the surface energies and Laplace pressures was used to prepare artificial fibers with the capacity to transport water droplets in the reverse direction, that is, from the spindle knots toward the joints. The relative wettability of the spindle knots and joints was tuned by changing the spindle knots' chemical composition or the roughness (Bai et al., 2010). Interestingly, artificial fibers were prepared to enable in situ switching of the directional water droplet movement by introducing a stimulus-responsive material onto the spindle knots (Feng et al., 2013; Hou et al., 2013). Thermo-responsive copolymer poly(methyl methacrylate)-bpoly( $N$-isopropylacrylamide) (PMMA-b-PNIPAAm) or photosensitive azobenzene polymers have been introduced into spindle knots. PMMA-b-PNIPAAm-modified spindle knots displayed a wettability that could be tuned by adjusting the environmental temperature below or above the lower critical solution temperature (LCST) of PNIPAAm. This stimulus switched the direction 
of the water droplets' movement (Hou et al., 2013). Photosensitive azobenzene polymer-modified spindle knots permitted control over the wettability and, therefore, the droplet movement direction via UV-vis irradiation, which transformed the molecular configuration of the azobenzene polymer from a less hydrophilic to a more hydrophilic state (Feng et al., 2013).

\section{Silk-Inspired Thermal Materials}

Silkworms weave cocoons to protect the pupae from extremely cold weather. The cocoon wall is a multilayer hierarchical fiber-based structure that traps air within the cocoon to provide thermal insulation. The still air is retained within the cocoon wall, even in the presence of wind, by depositing a calcium oxalate crystal layer on the outer surface of the cocoon wall. This layer reduces wind penetration (Zhang et al., 2013; Tao et al., 2015). With this understanding in mind, Wang et al. (2013) fabricated thermally insulating hollow biomorphic fibers using silkworm silk as the templates (the left image in Figure 4E). The silk fibers were immersed in an $\mathrm{AlCl}_{3}$ solution and dried at $70^{\circ} \mathrm{C}$ over $24 \mathrm{~h}$. An alumina layer formed on the surfaces of the silk fibers during an oxidation reaction. The silk fibers themselves were removed by heating, yielding free-standing alumina fibers with a hollow core (Wang et al., 2013). The fibers showed better thermo-insulating properties than traditional alumina fibers due to their hollow structures and infrared absorbing properties (Wang et al., 2013).

In general, bulk polymers have a very low thermal conductivity owing to strong photon scattering within the material (Chae and Kumar, 2008). Wang et al. recently found that dragline silk is a thermally conductive material with a thermal conductivity of $340 \mathrm{~W}^{-1} \mathrm{~K}^{-1}$ in its relaxed state ( $0 \%$ strain). The thermal conductivity may be further improved to $416 \mathrm{~W}^{-1} \mathrm{~K}^{-1}$ simply by stretching the fiber by $19.7 \%$ (Huang et al., 2012). The inherently high thermal conductivity of dragline silk is largely attributed to its crystal/non-crystal hierarchical internal structure. The nanofibrils are intensely packed in the dragline silk fibers with few defects, leading to a high thermal conductivity. The silk's thermal conductivity enhances after stretching due to an increase in the alignment of both the $\beta$-sheet crystal structure and the helical non-crystal structure (the right image in Figure 4E), thereby further enhancing photon conduction (Huang et al., 2012).

Prior to Wang's work, researchers recognized the effects of polymer chain orientation on the thermal conductivity of the polymer fibers (Shen et al., 2010). Chen et al. fabricated highquality ultra-drawn polyethylene nanofibers with a thermal conductivity as high as $\sim 10^{4} \mathrm{~W} \mathrm{~m}^{-1} \mathrm{~K}^{-1}$, larger than the thermal conductivities of half of the pure metals, including platinum, iron, and nickel (Shen et al., 2010). The high thermal conductivity was attributed to the restructuring of the polyethylene chains to form large crystals along the drawing direction after stretching, which decreased the defect density in the fibers and made the fibers ideal single crystalline fibers (Shen et al., 2010).

\section{Spider Web Network-Inspired Materials}

Buehler's group examined the mechanism by which the nonlinear mechanical characteristics of single silk fibers contribute to the integrity and performance of a spider web through web deformation experiments and atomistic simulations (Figure 4F)
(Cranford et al., 2012). The non-linear mechanical response to strain derives from the inherent semi-amorphous/ $\beta$-sheet nanocrystal hierarchical molecular structure of the silk fibers. Under relatively low stress, semi-amorphous domains permit entropic unfolding, which softens the stress-strain curves. Once unfolding is complete, stress is transferred to the rigid $\beta$-sheet crystal domains, leading to a sharp increase in the stress. These unique mechanical properties of single silk fibers localize loadinduced deformations by sacrificing the loaded fibers while maintaining the integrity of the web. This model offers a good explanation of why most natural webs are not intact in structure but remain functional for a spider's use (Cranford et al., 2012). The sacrifice of individual silk fibers to avoid damaging the whole web system has provided crucial inspiration for the design of new advanced 3D structure.

Recently, the same group prepared PDMS-based artificial spider webs using $3 \mathrm{D}$ printing to study how the geometrical arrangement of the silk fibers in a web influenced the web's mechanical performance (Qin et al., 2015). They found that the ratio of the radial silk diameter to the spiral silk diameter played a key role in tuning the mechanical response of the whole web to load. A homogeneous distribution of fibers with a radial/spiral ratio of $\sim 1$ tended to localize loading, whereas a heterogeneous distribution with much thicker radial silk fibers tended to distribute loading. This finding agrees well with the designs implemented naturally by spiders. Small webs built by garden spiders consist of radial and spiral silk fibers that are similar in size, which provides the maximum web strength against point loading by small prey. By contrast, giant webs built by spiders in rainforests are used to catch much larger prey; therefore, the spiders weave their webs with much thicker radial silk fibers to maximize the web strength against distributed loading (Qin et al., 2015).

\section{Non-Web Spider Silk Materials}

Besides aforementioned web silk, spiders also produce other types of silk, including pyriform silk, aciniform silk, and tubuliform/cylindriform silk for different uses, which also provide a lot of inspiration to fabricate new materials. Spiders produce attachment disks spun from pyriform silk to anchor their webs to diverse substrates. Cobweb spiders produce two types of attachment disks with distinct architectures using the same pyriform silk: "staple-pin" and "dendritic" disks (Sahni et al., 2012). "Stablepin" disk firmly attaches the dragline silk to the substrate and "dendritic" disk weakly attaches the gumfoot silk to the substrate, the reason behind the difference in adhesion strengths of the two disks is the peeling angles. Small peeling angle of "stable-in" disk is the secret of high adhesion strength; on the other hand, dendritic disk is peeled at much higher angles, resulting in its much lower adhesion strength. With this understating, synthetic adhesive attachment disks inspired by spider have been prepared. Jain et al. (2014) fabricated artificial attachment disk with a similar architecture to spider's "stable-pin" disks using polyurethane electrospun fibers. The adhesion energy and peeling forces can be controlled by adjusting the spacing of fibers and the surface energy of the substrate (Jain et al., 2014).

Spiders fabricate egg case using tubuliform/cylindriform silks to protect the egg from predator, because of their high 
toughness. At least three different proteins have been found in tubuliform silk: tubuliform spidroin 1 (TuSp1), egg case protein 1 and 2 (ECP-1 and ECP-2). Tutuliform silks is the second most studied spider fiber following the dragline silk and the primary sequence and structure of tobuliform silk proteins have been clearly demonstrated (Lin et al., 2009, 2013; Gnesa et al., 2012). Lin et al. (2013) produced TuSp1 consisting of both repetitive and conserved terminal domains using recombinant DNA technology, and the artificial fibers spun from the recombinant TuSp1 showed outstanding mechanical properties.

Spiders produce aciniform silk to wrap and immobilize prey because aciniform silks possess the highest toughness out of all the spider silks including the famous dragline silk. Acriniform silk is also used to form the soft inner layer of egg case. Tremblay et al. (2015) found that the high toughness of aciniform silk is related to the primary sequence of spidroin and the distinctive mixture of $\alpha$-helical, $\beta$-sheet, and non-canonical secondary structures. We expect that well understanding of the hierarchical architecture about these silks will inspire to the designs and development of advanced materials.

\section{Artificial Silk Fiber Prepared by Biomimetic Spinning}

Artificial spinning platforms have been designed to mimic the geometric construction of silkworm/spider spinning ducts, and artificial silk fibers have been prepared. Rammensee et al. (2008) designed a biomimetic microfluidic device in which ions and $\mathrm{pH}$ gradients were established along the elongational flow. Silk formation of a MaSp2 analog has been achieved using this device under similar condition to natural spider spinning duct. Kinahan et al. (2011) designed a microfluidic chip with a cross channel to prepare strong artificial silk fibroin fiber. PEO solution was chosen as the outer stream to apply shear stress on the silk fibroin core stream, and methanol bath was used to collect, dehydrate, and crystallize silk fiber. Because silk fibroin chains were aligned under the shear stress, the mechanical strength of the fibers could

\section{REFERENCES}

Altman, G. H., Diaz, F., Jakuba, C., Calabro, T., Horan, R. L., Chen, J., et al. (2003). Silk-based biomaterials. Biomaterials 24, 401-416. doi:10.1016/ S0142-9612(02)00353-8

An, B., Hinman, M. B., Holland, G. P., Yarger, J. L., and Lewis, R. V. (2011). Inducing $\boldsymbol{\beta}$-sheets formation in synthetic spider silk fibers by aqueous post-spin stretching. Biomacromolecules 12, 2375-2381. doi:10.1021/bm200463e

Askarieh, G., Hedhammar, M., Nordling, K., Saenz, A., Casals, C., Rising, A., et al. (2010). Self-assembly of spider silk proteins is controlled by a $\mathrm{pH}$-sensitive relay. Nature 465, 236-238. doi:10.1038/nature08962

Bai, H., Tian, X., Zheng, Y., Ju, J., Zhao, Y., and Jiang, L. (2010). Direction controlled driving of tiny water drops on bioinspired artificial spider silks. Adv. Mater. 22, 5521-5525. doi:10.1002/adma.201003169

Behanna, H. A., Donners, J. J. J. M., Gordon, A. C., and Stupp, S. I. (2005). Coassembly of amphiphiles with opposite peptide polarities into nanofibers. J. Am. Chem. Soc. 127, 1193-1200. doi:10.1021/ja044863u

Beun, L. H., Beaudoux, X. J., Kleijn, J. M., De Wolf, F. A., and Cohen Stuart, M. A. (2012). Self-assembly of silk-collagen-like triblock copolymers resembles a supramolecular living polymerization. ACS Nano 6, 133-140. doi:10.1021/ nn203092u

Beun, L. H., Storm, I. M., Werten, M. W. T., De Wolf, F. A., Cohen Stuart, M. A., and De Vries, R. (2014). From micelles to fibers: balancing self-assembling be relatively high, and this strength could be further improved by post-drawing (Kinahan et al., 2011). Luo et al. (2014) designed a biomimetic microfluidic chip with the shear and elongation conditions similar to the spinning duct of spider and silkworm. Regenerated silk fibroin solutions with a very high concentration (50 wt\%) was prepared and injected into the microchip as a spinning dope. Fibers were extruded out of the outlet and reeled on a rotating roller in air. The fibers were post-drawn in ethanol solution to further improve the mechanical property. The artificial fiber was tougher than the degummed natural silkworm silk (Luo et al., 2014).

\section{CONCLUSION AND OUTLOOK}

This review has outlined the sequence-structure-property interplay observed in natural silks and overviewed how smart materials are fabricated by mimicking natural silks. Significant progress in understanding the silk proteins' self-assembly, natural spinning process, and structure-property interplay has been achieved over the past decade, and many hidden secrets lie behind silk production and structure have been unveiled. This progress enabled the development of new materials inspired by natural silk. We expect that a much deeper understanding of the outstanding properties of silks will inspire researchers to design novel functional materials and to apply in diverse fields.

\section{AUTHOR CONTRIBUTIONS}

Prof. S-HL is the corresponding author and contributed to writing. Dr. JC contributed to data collecting and writing.

\section{FUNDING}

This work was supported by National Research Foundation of Korea (NRF-2015R1A2A1A09004998), Republic of Korea.

and random coiling domains in ph-responsive silk-collagen-like protein-based polymers. Biomacromolecules 15, 3349-3357. doi:10.1021/bm500826y

Bucak, S., Cenker, C., Nasir, I., Olsson, U., and Zackrisson, M. (2009). Peptide nanotube nematic phase. Langmuir 25, 4262-4265. doi:10.1021/la804175h

Castelletto, V., Hamley, I. W., Segarra-Maset, M. D., Berdugo Gumbau, C., Miravet, J. F., Escuder, B., et al. (2014). Tuning chelation by the surfactant-like peptide $\mathrm{A}(6) \mathrm{H}$ using predetermined $\mathrm{pH}$ values. Biomacromolecules 15, 591-598. doi:10.1021/bm401640j

Castelletto, V., Nutt, D. R., Hamley, I. W., Bucak, S., Cenker, C., and Olsson, U. (2010). Structure of single-wall peptide nanotubes: in situ flow aligning X-ray diffraction. Chem. Commun. 46, 6270-6272. doi:10.1039/C0CC00212G

Cenker, C. C., Bucak, S., and Olsson, U. (2011). Nanotubes and bilayers in a model peptide system. Soft Matter 7, 4868-4875. doi:10.1039/C0SM01186J

Cenker, C. C., Bucak, S., and Olsson, U. (2014). Aqueous self-assembly within the homologous peptide series AnK. Langmuir 30, 10072-10079. doi:10.1021/ la5016324

Chae, H. G., and Kumar, S. (2008). Making strong fibers. Science 319, 908-909. doi:10.1126/science.1153911

Chae, S.-K., Kang, E., Khademhosseini, A., and Lee, S.-H. (2013). Micro/nanometer-scale fiber with highly ordered structures by mimicking the spinning process of silkworm. Adv. Mater. 25, 3071-3078. doi:10.1002/adma.201300837

Chen, C., Pan, F., Zhang, S., Hu, J., Cao, M., Wang, J., et al. (2010). Antibacterial activities of short designer peptides: a link between propensity for nanostructuring 
and capacity for membrane destabilization. Biomacromolecules 11, 402-411. doi: $10.1021 / \mathrm{bm} 901130 \mathrm{u}$

Cheng, J., Park, M., and Hyun, J. (2014a). Simple conditions for large morphological variations in thermoresponsive biopolymeric microstructures. Chem. Commun. 50, 2954-2957. doi:10.1039/C3CC49044K

Cheng, Y., Zheng, F., Lu, J., Shang, L., Xie, Z., Zhao, Y., et al. (2014b). Bioinspired multicompartmental microfibers from microfluidics. Adv. Mater. 26, 51845190. doi:10.1002/adma.201400798

Cheng, J., Park, M., Lim, D. W., and Hyun, J. (2013). Polypeptide microgel capsules as drug carriers. Macromol. Res. 21, 1163-1166. doi:10.1007/ s13233-013-1167-6

Claussen, R. C., Rabatic, B. M., and Stupp, S. I. (2003). Aqueous self-assembly of unsymmetric peptide bolaamphiphiles into nanofibers with hydrophilic cores and surfaces. J. Am. Chem. Soc. 125, 12680-12681. doi:10.1021/ja035882r

Cranford, S. W., Tarakanova, A., Pugno, N. M., and Buehler, M. J. (2012). Nonlinear material behaviour of spider silk yields robust webs. Nature 482, 72-76. doi:10.1038/nature10739

Croisier, E., Liang, S., Schweizer, T., Balog, S., Mionic, M., Snellings, R., et al. (2014). A toolbox of oligopeptide-modified polymers for tailored elastomers. Nat. Commun. 5, 4728. doi:10.1038/ncomms5728

Currie, H. A., Deschaume, O., Naik, R. R., Perry, C. C., and Kaplan, D. L. (2011). Genetically engineered chimeric silk-silver binding proteins. Adv. Funct. Mater. 21, 2889-2895. doi:10.1002/adfm.201100249

Davis, V. A., Parra-Vasquez, A. N. G., Green, M. J., Rai, P. K., Behabtu, N., Prieto, V., et al. (2009). True solutions of single-walled carbon nanotubes for assembly into macroscopic materials. Nat. Nanotechnol. 4, 830-834. doi:10.1038/ nnano.2009.302

Dong, H., Wang, N., Wang, L., Bai, H., Wu, J., Zheng, Y., et al. (2012). Bioinspired electrospun knotted microfibers for fog harvesting. Chemphyschem 13, 1153-1156. doi:10.1002/cphc.201100957

Ericson, L. M., Fan, H., Peng, H., Davis, V. A., Zhou, W., Sulpizio, J., et al. (2004). Macroscopic, neat, single-walled carbon nanotube fibers. Science 305, 1447-1450. doi:10.1126/science.1101398

Fang, G., Zheng, Z., Yao, J., Chen, M., Tang, Y., Zhong, J., et al. (2015). Tough protein-carbon nanotube hybrid fibers comparable to natural spider silks. J. Mater. Chem. B 3, 3940-3947. doi:10.1039/C5TB00448A

Feng, S., Hou, Y., Xue, Y., Gao, L., Jiang, L., and Zheng, Y. (2013). Photo-controlled water gathering on bio-inspired fibers. Soft Matter 9, 9294-9297. doi:10.1039/ C3SM51517F

Gnesa, E., Hsia, Y., Yarger, J. L., Weber, W., Lin-Cereghino, J., Lin-Cereghino, G., et al. (2012). Conserved C-terminal domain of spider tubuliform spidroin 1 contributes to extensibility in synthetic fibers. Biomacromolecules 13, 304-312. doi:10.1021/bm201262n

Golinska, M. D., Wlodarczyk-Biegun, M. K., Werten, M. W. T., Cohen Stuart, M. A., De Wolf, F. A., and De Vries, R. (2014). Dilute self-healing hydrogels of silk-collagen-like block copolypeptides at neutral pH. Biomacromolecules 15, 699-706. doi:10.1021/bm401682n

Gomes, S. C., Leonor, I. B., Mano, J. F., Reis, R. L., and Kaplan, D. L. (2011). Antimicrobial functionalized genetically engineered spider silk. Biomaterials 32, 4255-4266. doi:10.1016/j.biomaterials.2011.02.040

Graf, J., Iwamoto, Y., Sasaki, M., Martin, G. R., Kleinman, H. K., Robey, F. A., et al. (1987). Identification of an amino acid sequence in laminin mediating cell attachment, chemotaxis, and receptor binding. Cell 48, 989-996. doi:10.1016/0092-8674(87)90707-0

Grant, D. S., Tashiro, K.-I., Segui-Real, B., Yamada, Y., Martin, G. R., and Kleinman, H. K. (1989). Two different laminin domains mediate the differentiation of human endothelial cells into capillary-like structures in vitro. Cell 58, 933-943. doi:10.1016/0092-8674(89)90945-8

Gus'kova, O. A., Khalatur, P. G., Bäuerle, P., and Khokhlov, A. R. (2008). Silkinspired 'molecular chimeras': atomistic simulation of nanoarchitectures based on thiophene-peptide copolymers. Chem. Phys. Lett. 461, 64-70. doi:10.1016/j. cplett.2008.06.058

Hagn, F., Eisoldt, L., Hardy, J. G., Vendrely, C., Coles, M., Scheibel, T., et al. (2010). A conserved spider silk domain acts as a molecular switch that controls fibre assembly. Nature 465, 239-242. doi:10.1038/nature08936

Hamley, I. W., Dehsorkhi, A., Castelletto, V., Seitsonen, J., Ruokolainen, J., and Iatrou, H. (2013). Self-assembly of a model amphiphilic oligopeptide incorporating an arginine headgroup. Soft Matter 9, 4794-4801. doi:10.1039/ c3sm50303h
Hartgerink, J. D., Beniash, E., and Stupp, S. I. (2001). Self-assembly and mineralization of peptide-amphiphile nanofibers. Science 294, 1684-1688. doi:10.1126/ science. 1063187

Hartgerink, J. D., Beniash, E., and Stupp, S. I. (2002). Peptide-amphiphile nanofibers: a versatile scaffold for the preparation of self-assembling materials. Proc. Natl. Acad. Sci. U.S.A. 99, 5133-5138. doi:10.1073/pnas.072699999

He, Y.-X., Zhang, N.-N., Li, W.-F., Jia, N., Chen, B.-Y., Zhou, K., et al. (2012). $\mathrm{N}$-terminal domain of Bombyx mori fibroin mediates the assembly of silk in response to $\mathrm{pH}$ decrease. J. Mol. Biol. 418, 197-207. doi:10.1016/j. jmb.2012.02.040

Heim, M., Romer, L., and Scheibel, T. (2010). Hierarchical structures made of proteins. The complex architecture of spider webs and their constituent silk proteins. Chem. Soc. Rev. 39, 156-164. doi:10.1039/B813273A

Hermanson, K. D., Huemmerich, D., Scheibel, T., and Bausch, A. R. (2007). Engineered microcapsules fabricated from reconstituted spider silk. Adv. Mater. 19, 1810-1815. doi:10.1002/adma.200602709

Hirayama, K., Okitsu, T., Teramae, H., Kiriya, D., Onoe, H., and Takeuchi, S. (2013). Cellular building unit integrated with microstrand-shaped bacterial cellulose. Biomaterials 34, 2421-2427. doi:10.1016/j.biomaterials.2012.12.013

Hou, Y., Gao, L., Feng, S., Chen, Y., Xue, Y., Jiang, L., et al. (2013). Temperaturetriggered directional motion of tiny water droplets on bioinspired fibers in humidity. Chem. Commun. 49, 5253-5255. doi:10.1039/C3CC41060A

Huang, X., Liu, G., and Wang, X. (2012). New secrets of spider silk: exceptionally high thermal conductivity and its abnormal change under stretching. Adv. Mater. 24, 1482-1486. doi:10.1002/adma.201104668

Huemmerich, D., Helsen, C. W., Quedzuweit, S., Oschmann, J., Rudolph, R., and Scheibel, T. (2004). Primary structure elements of spider dragline silks and their contribution to protein solubility $\dagger$. Biochemistry 43, 13604-13612. doi:10.1021/ bi048983q

Hwang, C. M., Khademhosseini, A., Park, Y., Sun, K., and Lee, S.-H. (2008). Microfluidic chip-based fabrication of PLGA microfiber scaffolds for tissue engineering. Langmuir 24, 6845-6851. doi:10.1021/la800253b

Hwang, C. M., Park, Y., Park, J. Y., Lee, K., Sun, K., Khademhosseini, A., et al. (2009). Controlled cellular orientation on PLGA microfibers with defined diameters. Biomed. Microdevices 11, 739-746. doi:10.1007/s10544-009-9287-7

Jain, D., Sahni, V., and Dhinojwala, A. (2014). Synthetic adhesive attachment discs inspired by spider's pyriform silk architecture. J. Polym. Sci. B Polym. Phys. 52, 553-560. doi:10.1002/polb.23453

Jeong, W., Kim, J., Kim, S., Lee, S., Mensing, G., and Beebe, D. J. (2004). Hydrodynamic microfabrication via "on the fly" photopolymerization of microscale fibers and tubes. Lab. Chip 4, 576-580. doi:10.1039/B411249K

Jin, H.-J., and Kaplan, D. L. (2003). Mechanism of silk processing in insects and spiders. Nature 424, 1057-1061. doi:10.1038/nature01809

Jun, Y., Kang, A. R., Lee, J. S., Park, S.-J., Lee, D. Y., Moon, S.-H., et al. (2014a). Microchip-based engineering of super-pancreatic islets supported by adipose-derived stem cells. Biomaterials 35, 4815-4826. doi:10.1016/j. biomaterials.2014.02.045

Jun, Y., Kang, E., Chae, S., and Lee, S.-H. (2014b). Microfluidic spinning of micro- and nano-scale fibers for tissue engineering. Lab. Chip 14, 2145-2160. doi:10.1039/C3LC51414E

Jun, Y., Kim, M. J., Hwang, Y. H., Jeon, E. A., Kang, A. R., Lee, S.-H., et al. (2013). Microfluidics-generated pancreatic islet microfibers for enhanced immunoprotection. Biomaterials 34, 8122-8130. doi:10.1016/j.biomaterials.2013.07.079

Kang, A., Park, J., Ju, J., Jeong, G. S., and Lee, S.-H. (2014). Cell encapsulation via microtechnologies. Biomaterials 35, 2651-2663. doi:10.1016/j. biomaterials.2013.12.073

Kang, E., Choi, Y. Y., Chae, S.-K., Moon, J.-H., Chang, J.-Y., and Lee, S.-H. (2012). Microfluidic spinning of flat alginate fibers with grooves for cell-aligning scaffolds. Adv. Mater. 24, 4271-4277. doi:10.1002/adma.201201232

Kang, E., Jeong, G. S., Choi, Y. Y., Lee, K. H., Khademhosseini, A., and Lee, S.-H. (2011). Digitally tunable physicochemical coding of material composition and topography in continuous microfibres. Nat. Mater. 10, 877-883. doi:10.1038/ nmat3108

Kang, E., Shin, S.-J., Lee, K. H., and Lee, S.-H. (2010). Novel PDMS cylindrical channels that generate coaxial flow, and application to fabrication of microfibers and particles. Lab. Chip 10, 1856-1861. doi:10.1039/C002695F

Keten, S., Xu, Z., Ihle, B., and Buehler, M. J. (2010). Nanoconfinement controls stiffness, strength and mechanical toughness of [beta]-sheet crystals in silk. Nat. Mater. 9, 359-367. doi:10.1038/nmat2704 
Kim, D.-H., Viventi, J., Amsden, J. J., Xiao, J., Vigeland, L., Kim, Y.-S., et al. (2010). Dissolvable films of silk fibroin for ultrathin conformal bio-integrated electronics. Nat. Mater. 9, 511-517. doi:10.1038/nmat2745

Kim, S., Marelli, B., Brenckle, M. A., Mitropoulos, A. N., Gil, E.-S., Tsioris, K., et al. (2014). All-water-based electron-beam lithography using silk as a resist. Nat. Nanotechnol. 9, 306-310. doi:10.1038/nnano.2014.47

Kinahan, M. E., Filippidi, E., Köster, S., Hu, X., Evans, H. M., Pfohl, T., et al. (2011). Tunable silk: using microfluidics to fabricate silk fibers with controllable properties. Biomacromolecules 12, 1504-1511. doi:10.1021/bm1014624

Kiriya, D., Ikeda, M., Onoe, H., Takinoue, M., Komatsu, H., Shimoyama, Y., et al. (2012a). Meter-long and robust supramolecular strands encapsulated in hydrogel jackets. Angew. Chem. Int. Ed. 51, 1553-1557. doi:10.1002/anie.201104043

Kiriya, D., Kawano, R., Onoe, H., and Takeuchi, S. (2012b). Microfluidic control of the internal morphology in nanofiber-based macroscopic cables. Angew. Chem. Int. Ed. 51, 7942-7947. doi:10.1002/anie.201202078

Kis, A., Csanyi, G., Salvetat, J. P., Lee, T.-N., Couteau, E., Kulik, A. J., et al. (2004). Reinforcement of single-walled carbon nanotube bundles by intertube bridging. Nat. Mater. 3, 153-157. doi:10.1038/nmat1076

Koski, K. J., Akhenblit, P., Mckiernan, K., and Yarger, J. L. (2013). Non-invasive determination of the complete elastic moduli of spider silks. Nat. Mater. 12, 262-267. doi:10.1038/nmat3549

Kundu, B., Kurland, N. E., Bano, S., Patra, C., Engel, F. B., Yadavalli, V. K., et al. (2014). Silk proteins for biomedical applications: bioengineering perspectives. Prog. Polym. Sci. 39, 251-267. doi:10.1016/j.progpolymsci.2013.09.002

Leal-Egaña, A., Lang, G., Mauerer, C., Wickinghoff, J., Weber, M., Geimer, S., et al. (2012). Interactions of fibroblasts with different morphologies made of an engineered spider silk protein. Adv. Eng. Mater. 14, B67-B75. doi:10.1002/ adem. 201180072

Leal-Egana, A., and Scheibel, T. (2012). Interactions of cells with silk surfaces. J. Mater. Chem. 22, 14330-14336. doi:10.1039/C2JM31174G

Lee, K. H., Shin, S. J., Kim, C.-B., Kim, J. K., Cho, Y. W., Chung, B. G., et al. (2010). Microfluidic synthesis of pure chitosan microfibers for bio-artificial liver chip. Lab. Chip 10, 1328-1334. doi:10.1039/B924987G

Lee, K. H., Shin, S. J., Park, Y., and Lee, S.-H. (2009). Synthesis of cell-laden alginate hollow fibers using microfluidic chips and microvascularized tissue-engineering applications. Small 5, 1264-1268. doi:10.1002/smll.200801667

Lin, Y., Xia, X., Wang, M., Wang, Q., An, B., Tao, H., et al. (2014). Genetically programmable thermoresponsive plasmonic gold/silk-elastin protein core/ shell nanoparticles. Langmuir 30, 4406-4414. doi:10.1021/la403559t

Lin, Z., Deng, Q., Liu, X.-Y., and Yang, D. (2013). Engineered large spider eggcase silk protein for strong artificial fibers. Adv. Mater. 25, 1216-1220. doi:10.1002/ adma.201204357

Lin, Z., Huang, W., Zhang, J., Fan, J.-S., and Yang, D. (2009). Solution structure of eggcase silk protein and its implications for silk fiber formation. Proc. Natl. Acad. Sci. U.S.A. 106, 8906-8911. doi:10.1073/pnas.0813255106

Liu, Y., Shao, Z., and Vollrath, F. (2005). Relationships between supercontraction and mechanical properties of spider silk. Nat. Mater. 4, 901-905. doi:10.1038/ nmat 1534

Luo, J., Zhang, L., Peng, Q., Sun, M., Zhang, Y., Shao, H., et al. (2014). Tough silk fibers prepared in air using a biomimetic microfluidic chip. Int. J. Biol. Macromol. 66, 319-324. doi:10.1016/j.ijbiomac.2014.02.049

Martens, A. A., Portale, G., Werten, M. W. T., De Vries, R. J., Eggink, G., Cohen Stuart, M. A., et al. (2009). Triblock protein copolymers forming supramolecular nanotapes and pH-responsive gels. Macromolecules 42, 1002-1009. doi:10.1021/ma801955q

Megeed, Z., Cappello, J., and Ghandehari, H. (2002). Controlled release of plasmid DNA from a genetically engineered silk-elastinlike hydrogel. Pharm. Res. 19, 954-959. doi:10.1023/a:1016406120288

Megeed, Z., Haider, M., Li, D. Q., O’Malley, B. W., Cappello, J., and Ghandehari, H. (2004). In vitro and in vivo evaluation of recombinant silk-elastinlike hydrogels for cancer gene therapy. J. Control. Release 94, 433-445. doi:10.1016/j. jconrel.2003.10.027

Naraghi, M., Bratzel, G. H., Filleter, T., An, Z., Wei, X., Nguyen, S. T., et al. (2013). Atomistic investigation of load transfer between DWNT bundles "crosslinked” by PMMA oligomers. Adv. Funct. Mater. 23, 1883-1892. doi:10.1002/ adfm. 201201358

Numata, K., and Kaplan, D. L. (2010). Silk-based gene carriers with cell membrane destabilizing peptides. Biomacromolecules 11, 3189-3195. doi:10.1021/ bm101055m
Numata, K., Reagan, M. R., Goldstein, R. H., Rosenblatt, M., and Kaplan, D. L. (2011). Spider silk-based gene carriers for tumor cell-specific delivery. Bioconjug. Chem. 22, 1605-1610. doi:10.1021/bc200170u

Omenetto, F. G., and Kaplan, D. L. (2010). New opportunities for an ancient material. Science 329, 528-531. doi:10.1126/science.1188936

Onoe, H., Okitsu, T., Itou, A., Kato-Negishi, M., Gojo, R., Kiriya, D., et al. (2013). Metre-long cell-laden microfibres exhibit tissue morphologies and functions. Nat. Mater. 12, 584-590. doi:10.1038/nmat3606

Opell, B. D., and Hendricks, M. L. (2009). The adhesive delivery system of viscous capture threads spun by orb-weaving spiders. J. Exp. Biol. 212, 3026-3034. doi:10.1242/jeb.030064

Opell, B. D., and Hendricks, M. L. (2010). The role of granules within viscous capture threads of orb-weaving spiders. J. Exp. Biol. 213, 339-346. doi:10.1242/ jeb.036947

Peng, H., Jain, M., Li, Q., Peterson, D. E., Zhu, Y., and Jia, Q. (2008). Vertically aligned pearl-like carbon nanotube arrays for fiber spinning. J. Am. Chem. Soc. 130, 1130-1131. doi:10.1021/ja077767c

Porter, D., Guan, J., and Vollrath, F. (2013). Spider silk: super material or thin fibre? Adv. Mater. 25, 1275-1279. doi:10.1002/adma.201204158

Qin, Z., and Buehler, M. J. (2013). Spider silk: webs measure up. Nat. Mater. 12, 185-187. doi:10.1038/nmat3578

Qin, Z., Compton, B. G., Lewis, J. A., and Buehler, M. J. (2015). Structural optimization of 3D-printed synthetic spider webs for high strength. Nat. Commun. 6, 7038. doi:10.1038/ncomms8038

Qiu, F., Chen, Y., and Zhao, X. (2009). Comparative studies on the self-assembling behaviors of cationic and catanionic surfactant-like peptides. J. Colloid Interface Sci. 336, 477-484. doi:10.1016/j.jcis.2009.04.014

Rammensee, S., Huemmerich, D., Hermanson, K. D., Scheibel, T., and Bausch, A. R. (2006). Rheological characterization of hydrogels formed by recombinantly produced spider silk. Appl. Phys. A 82, 261-264. doi:10.1007/s00339-005-3431-x

Rammensee, S., Slotta, U., Scheibel, T., and Bausch, A. R. (2008). Assembly mechanism of recombinant spider silk proteins. Proc. Natl. Acad. Sci. U.S.A. 105, 6590-6595. doi:10.1073/pnas.0709246105

Rathore, O., and Sogah, D. Y. (2001a). Nanostructure formation through $\boldsymbol{\beta}$-sheet self-assembly in silk-based materials. Macromolecules 34, 1477-1486. doi: $10.1021 / \mathrm{ma} 001553 \mathrm{x}$

Rathore, O., and Sogah, D. Y. (2001b). Self-assembly of $\boldsymbol{\beta}$-sheets into nanostructures by poly(alanine) segments incorporated in multiblock copolymers inspired by spider silk. J. Am. Chem. Soc. 123, 5231-5239. doi:10.1021/ja004030d

Rockwood, D. N., Preda, R. C., Yucel, T., Wang, X., Lovett, M. L., and Kaplan, D. L. (2011). Materials fabrication from Bombyx mori silk fibroin. Nat. Protoc. 6, 1612-1631. doi:10.1038/nprot.2011.379

Sahni, V., Blackledge, T. A., and Dhinojwala, A. (2010). Viscoelastic solids explain spider web stickiness. Nat. Commun. 1, 19. doi:10.1038/ncomms1019

Sahni, V., Harris, J., Blackledge, T. A., and Dhinojwala, A. (2012). Cobweb-weaving spiders produce different attachment discs for locomotion and prey capture. Nat. Commun. 3, 1106. doi:10.1038/ncomms2099

Sanchez, C., Arribart, H., and Giraud Guille, M. M. (2005). Biomimetism and bioinspiration as tools for the design of innovative materials and systems. Nat. Mater. 4, 277-288. doi:10.1038/nmat1339

Schacht, K., and Scheibel, T. (2014). Processing of recombinant spider silk proteins into tailor-made materials for biomaterials applications. Curr. Opin. Biotechnol. 29, 62-69. doi:10.1016/j.copbio.2014.02.015

Scheibel, T. (2004). Spider silks: recombinant synthesis, assembly, spinning, and engineering of synthetic proteins. Microb. Cell Fact. 3, 14. doi:10.1186/1475-2859-3-14

Schwarze, S., Zwettler, F. U., Johnson, C. M., and Neuweiler, H. (2013). The $\mathrm{N}$-terminal domains of spider silk proteins assemble ultrafast and protected from charge screening. Nat. Commun. 4, 2815. doi:10.1038/ncomms3815

Shah, R. N., Shah, N. A., Lim, M. M. D. R., Hsieh, C., Nuber, G., and Stupp, S. I. (2010). Supramolecular design of self-assembling nanofibers for cartilage regeneration. Proc. Natl. Acad. Sci. U.S.A. 107, 3293-3298. doi:10.1073/ pnas.0906501107

Shen, S., Henry, A., Tong, J., Zheng, R., and Chen, G. (2010). Polyethylene nanofibres with very high thermal conductivities. Nat. Nanotechnol. 5, 251-255. doi:10.1038/nnano.2010.27

Shin, S.-J., Park, J.-Y., Lee, J.-Y., Park, H., Park, Y.-D., Lee, K.-B., et al. (2007). “On the fly" continuous generation of alginate fibers using a microfluidic device. Langmuir 23, 9104-9108. doi:10.1021/la700818q 
Silva, L. P., and Rech, E. L. (2013). Unravelling the biodiversity of nanoscale signatures of spider silk fibres. Nat. Commun. 4, 3014. doi:10.1038/ ncomms 4014

Slotta, U., Hess, S., Spiess, K., Stromer, T., Serpell, L., and Scheibel, T. (2007). Spider silk and amyloid fibrils: a structural comparison. Macromol. Biosci. 7, 183-188. doi:10.1002/mabi.200600201

Smeenk, J. M., Otten, M. B. J., Thies, J., Tirrell, D. A., Stunnenberg, H. G., and Van Hest, J. C. M. (2005). Controlled assembly of macromolecular beta-sheet fibrils. Angew. Chem. Int. Ed. 44, 1968-1971. doi:10.1002/anie.200462415

Smeenk, J. M., Schön, P., Otten, M. B. J., Speller, S., Stunnenberg, H. G., and Van Hest, J. C. M. (2006). Fibril formation by triblock copolymers of silklike $\boldsymbol{\beta}$-sheet polypeptides and poly(ethylene glycol). Macromolecules 39, 2989-2997. doi:10.1021/ma0521654

Stellwagen, S. D., Opell, B. D., and Short, K. G. (2014). Temperature mediates the effect of humidity on the viscoelasticity of glycoprotein glue within the droplets of an orb-weaving spider's prey capture threads. J. Exp. Biol. 217, 1563-1569. doi:10.1242/jeb.097816

Tao, H., Kaplan, D. L., and Omenetto, F. G. (2012). Silk materials - a road to sustainable high technology. Adv. Mater. 24, 2824-2837. doi:10.1002/adma.201104477

Tao, P., Shang, W., Song, C., Shen, Q., Zhang, F., Luo, Z., et al. (2015). Bioinspired engineering of thermal materials. Adv. Mater. 27, 428-463. doi:10.1002/ adma.201401449

Tian, X., Bai, H., Zheng, Y., and Jiang, L. (2011). Bio-inspired heterostructured bead-on-string fibers that respond to environmental wetting. Adv. Funct. Mater. 21, 1398-1402. doi:10.1002/adfm.201002061

Tokareva, O., Jacobsen, M., Buehler, M., Wong, J., and Kaplan, D. L. (2014). Structure-function-property-design interplay in biopolymers: spider silk. Acta Biomater. 10, 1612-1626. doi:10.1016/j.actbio.2013.08.020

Tokareva, O., Michalczechen-Lacerda, V. A., Rech, E. L., and Kaplan, D. L. (2013). Recombinant DNA production of spider silk proteins. Microb. Biotechnol. 6, 651-663. doi:10.1111/1751-7915.12081

Tremblay, M.-L., Xu, L., Lefèvre, T., Sarker, M., Orrell, K. E., Leclerc, J., et al. (2015). Spider wrapping silk fibre architecture arising from its modular soluble protein precursor. Sci. Rep. 5, 11502. doi:10.1038/srep11502

Vauthey, S., Santoso, S., Gong, H. Y., Watson, N., and Zhang, S. G. (2002). Molecular self-assembly of surfactant-like peptides to form nanotubes and nanovesicles. Proc. Natl. Acad. Sci. U.S.A. 99, 5355-5360. doi:10.1073/pnas.072089599

Vepari, C., and Kaplan, D. L. (2007). Silk as a biomaterial. Prog. Polym. Sci. 32, 991-1007. doi:10.1016/j.progpolymsci.2007.05.013

Vollrath, F., Fairbrother, W. J., Williams, R. J. P., Tillinghast, E. K., Bernstein, D. T., Gallagher, K. S., et al. (1990). Compounds in the droplets of the orb spider's viscid spiral. Nature 345, 526-528. doi:10.1038/345526a0

Vollrath, F., and Knight, D. P. (2001). Liquid crystalline spinning of spider silk. Nature 410, 541-548. doi:10.1038/35069000

von Maltzahn, G., Vauthey, S., Santoso, S., and Zhang, S. U. (2003). Positively charged surfactant-like peptides self-assemble into nanostructures. Langmuir 19, 4332-4337. doi:10.1021/la026526+

Wang, J., Han, S., Meng, G., Xu, H., Xia, D., Zhao, X., et al. (2009). Dynamic self-assembly of surfactant-like peptides A(6)K and A(9)K. Soft Matter 5, 3870-3878. doi:10.1039/b901653h

Wang, T., Kong, S., Jia, Y., Chang, L., Wong, C., and Xiong, D. (2013). Synthesis and thermal conductivities of the biomorphic Al2O3 fibers derived from silktemplate. Int. J. Appl. Ceram. Tech. 10, 285-292. doi:10.1111/j.1744-7402.2012.02841.x

Wen, L., Tian, Y., and Jiang, L. (2015). Bioinspired super-wettability from fundamental research to practical applications. Angew. Chem. Int. Ed. 54, 3387-3399. doi:10.1002/anie.201409911

Widhe, M., Johansson, U., Hillerdahl, C.-O., and Hedhammar, M. (2013). Recombinant spider silk with cell binding motifs for specific adherence of cells. Biomaterials 34, 8223-8234. doi:10.1016/j.biomaterials.2013.07.058

Wohlrab, S., Müller, S., Schmidt, A., Neubauer, S., Kessler, H., Leal-Egaña, A., et al. (2012). Cell adhesion and proliferation on RGD-modified recombinant spider silk proteins. Biomaterials 33, 6650-6659. doi:10.1016/j. biomaterials.2012.05.069

Wong Po Foo, C., Patwardhan, S. V., Belton, D. J., Kitchel, B., Anastasiades, D., Huang, J., et al. (2006). Novel nanocomposites from spider silk-silica fusion (chimeric) proteins. Proc. Natl. Acad. Sci. U.S.A. 103, 9428-9433. doi:10.1073/ pnas.0601096103

Wu, M., Shuai, H., Cheng, Q., and Jiang, L. (2014). Bioinspired green composite lotus fibers. Angew. Chem. Int. Ed. 53, 3358-3361. doi:10.1002/anie.201310656

Xia, X.-X., Qian, Z.-G., Ki, C. S., Park, Y. H., Kaplan, D. L., and Lee, S. Y. (2010). Native-sized recombinant spider silk protein produced in metabolically engineered Escherichia coli results in a strong fiber. Proc. Natl. Acad. Sci. U.S.A. 107, 14059-14063. doi:10.1073/pnas.1003366107

Xia, X.-X., Wang, M., Lin, Y., Xu, Q., and Kaplan, D. L. (2014). Hydrophobic drug-triggered self-assembly of nanoparticles from silk-elastin-like protein polymers for drug delivery. Biomacromolecules 15, 908-914. doi:10.1021/ bm4017594

Xia, X.-X., Xu, Q., Hu, X., Qin, G., and Kaplan, D. L. (2011). Tunable self-assembly of genetically engineered silk-elastin-like protein polymers. Biomacromolecules 12, 3844-3850. doi:10.1021/bm201165h

Yan, J., Zhou, G., Knight, D. P., Shao, Z., and Chen, X. (2010). Wet-spinning of regenerated silk fiber from aqueous silk fibroin solution: discussion of spinning parameters. Biomacromolecules 11, 1-5. doi:10.1021/bm900840h

Yu, Y., Wen, H., Ma, J., Lykkemark, S., Xu, H., and Qin, J. (2014). Flexible fabrication of biomimetic bamboo-like hybrid microfibers. Adv. Mater. 26, 2494-2499. doi:10.1002/adma.201304974

Zhang, J., Rajkhowa, R., Li, J. L., Liu, X. Y., and Wang, X. G. (2013). Silkworm cocoon as natural material and structure for thermal insulation. Mater. Des. 49, 842-849. doi:10.1016/j.matdes.2013.02.006

Zhang, M., Fang, S., Zakhidov, A. A., Lee, S. B., Aliev, A. E., Williams, C. D., et al. (2005). Strong, transparent, multifunctional, carbon nanotube sheets. Science 309, 1215-1219. doi:10.1126/science.1115311

Zhang, S. (2003). Fabrication of novel biomaterials through molecular selfassembly. Nat. Biotechnol. 21, 1171-1178. doi:10.1038/nbt874

Zhang, S., Greenfield, M. A., Mata, A., Palmer, L. C., Bitton, R., Mantei, J. R., et al. (2010). A self-assembly pathway to aligned monodomain gels. Nat. Mater. 9, 594-601. doi:10.1038/nmat2778

Zhao, X., Nagai, Y., Reeves, P. J., Kiley, P., Khorana, H. G., and Zhang, S. (2006). Designer short peptide surfactants stabilize $\mathrm{G}$ protein-coupled receptor bovine rhodopsin. Proc. Natl. Acad. Sci. U.S.A. 103, 17707-17712. doi:10.1073/ pnas.0607167103

Zheng, Y., Bai, H., Huang, Z., Tian, X., Nie, F.-Q., Zhao, Y., et al. (2010). Directional water collection on wetted spider silk. Nature 463, 640-643. doi:10.1038/ nature08729

Zhou, C., Leng, B., Yao, J., Qian, J., Chen, X., Zhou, P., et al. (2006). Synthesis and characterization of multiblock copolymers based on spider dragline silk proteins. Biomacromolecules 7, 2415-2419. doi:10.1021/bm060199t

Zhou, G., Shao, Z., Knight, D. P., Yan, J., and Chen, X. (2009). Silk fibers extruded artificially from aqueous solutions of regenerated Bombyx mori silk fibroin are tougher than their natural counterparts. Adv. Mater. 21, 366-370. doi:10.1002/ adma.200800582

Conflict of Interest Statement: The authors declare that the research was conducted in the absence of any commercial or financial relationships that could be construed as a potential conflict of interest.

Copyright (c) 2016 Cheng and Lee. This is an open-access article distributed under the terms of the Creative Commons Attribution License (CC BY). The use, distribution or reproduction in other forums is permitted, provided the original author(s) or licensor are credited and that the original publication in this journal is cited, in accordance with accepted academic practice. No use, distribution or reproduction is permitted which does not comply with these terms. 